\title{
A systematic review on multiparametric MR imaging in prostate cancer detection
}

\author{
Roberta Fusco ${ }^{1 *}$, Mario Sansone ${ }^{2}$, Vincenza Granata ${ }^{1}$, Sergio Venanzio Setola ${ }^{1}$ and Antonella Petrillo ${ }^{1}$
}

\begin{abstract}
Background: Literature data suggest that multi-parametric Magnetic Resonance Imaging (MRI), including morphologic T2-weigthed images (T2-MRI) and functional approaches such as Dynamic Contrast Enhanced-MRI (DCE-MRI), Diffusion Weighted Imaging (DWI) and Magnetic Resonance Spectroscopic Imaging (MRSI), give an added value in the prostate cancer localization and local staging.

Methods: We performed a systematic review of literature about the role and the potentiality of morphological and functional MRI in prostate cancer, also in a multimodal / multiparametric approach, and we reported the diagnostic accuracy results for different imaging modalities and for different MR coil settings: endorectal coil (ERC) and phased array coil (PAC). Forest plots and receiver operating characteristic curves were performed. Risk of bias and the applicability at study level were calculated.

Results: Thirty three papers were identified for the systematic review. Sensitivity and specificity values were, respectively, for T2-MRI of $75 \%$ and of $60 \%$, for DCE-MRI of $80 \%$ and of $72 \%$, for MRSI of $89 \%$ and of $69 \%$, for combined T2-MRI and DCE-MRI of $87 \%$ and of $46 \%$, for combined T2-MRI and MRSI of 79\% and of 57\%, for combined T2-MRI, DWI and DCE-MRI of $81 \%$ and of $84 \%$, and for combined MRSI and DCE-MRI of $83 \%$ and of $83 \%$. For MRI studies performed with ERC we obtained a pooled sensitivity and specificity of $81 \%$ and of $66 \%$ while the pooled values for MRI studies performed with PAC were of $78 \%$ and of $64 \%$, respectively ( $p>0.05$ at McNemar test). No studies were excluded from the analysis based on the quality assessment.

Conclusions: ERC use yielded no additional benefit in terms of prostate cancer detection accuracy compared to multi-channel PAC use (71\% versus $68 \%$ ) while the use of additional functional imaging techniques (DCE-MRI, DWI and MRSI) in a multiparametric MRI protocol improves the accuracy of prostate cancer detection allowing both the early cure and the guidance of biopsy.
\end{abstract}

Keywords: Prostate cancer, Magnetic Resonance Spectroscopic Imaging, Diffusion Weighted Imaging, Dynamic Contrast Enhanced Imaging, Coil setting

\section{Background}

Approximately 180,890 new prostate cancers are expected in 2016 in the USA [1]. The most wellrecognized risk factors for the development of prostate cancer are old age, family history, testosterone, ethnic origin, environment and genetic factors [2]. One such potential environmental factor which has gained a great deal of recent attention is the development of chronic inflammation in the prostate due to a number of

\footnotetext{
* Correspondence: r.fusco@istitutotumori.na.it

${ }^{1}$ Radiology Unit, "Dipartimento di supporto ai percorsi oncologici Area

Diagnostica, Istituto Nazionale Tumori - IRCCS - Fondazione G. Pascale", Via

Mariano Semmola, Naples, Italy

Full list of author information is available at the end of the article
}

potential causes including infections, dietary factors, hormonal changes and/or other unknown environmental exposures [2]. The exact mechanisms of the progression of prostate gland into a cancer are not well characterized. The growing epidemiological studies have suggested that prostate tissue is prone to sexually transmitted infection with several viruses having oncogenic potential such as polyomaviruses, human papillomaviruses, and members of the herpes virus family [3-8].

Early detection of prostate cancer can lead to a complete cure [2-10]. Mainly, the diagnosis of prostate cancer is based on the results of ultrasonography (US)- 
guided transrectal biopsy. A random biopsy was typically performed to overcome the ultrasonography limits in prostate cancer detection and localization. However, a random biopsy has several disadvantages such as an increase in complications because of the unnecessary sampling of normal prostate tissue while cancer that is located outside the routine biopsy site may be missed. In addition, there may be difficulties in determining the site of a previous biopsy when repeating biopsy in a patient with a previous negative result and continuous high prostate-specific antigen (PSA) levels. A more advanced imaging modality is needed for accurate detection and localization of prostate cancer, as well as guidance of biopsy.

Magnetic resonance imaging (MRI) has been used to evaluate prostate anatomy and pathologies: it provides high-resolution images of the prostate and surrounding structures. T2-weighted magnetic resonance imaging (T2-MRI) with endorectal coil (ERC) and pelvic phased array coil (PAC) has been widely used for pre-treatment work-up of prostate cancer [2-17]. However, T2-MRI has substantial restrictions for depicting cancer in the transitional and central zones, because both cancer and normal tissues have low signal intensity. In addition, low signal intensity may be seen in the peripheral zone on T2-MRI in case of some noncancerous abnormal conditions, such as inflammation, biopsy related haemorrhage, post-radiation therapy fibrosis [15-22].

Other MRI modalities might be used to increase the diagnostic accuracy in prostate cancer detection and localization such as Magnetic Resonance Spectroscopic Imaging (MRSI), Dynamic Contrast Enhanced MR Imaging (DCE-MRI) and Diffusion Weighted Imaging (DWI).
MRSI measures metabolite levels in the tissue such as choline $(\mathrm{Ch})$, citrate $(\mathrm{Cit})$, creatine $(\mathrm{Cr})$, and various polyamines (spermine, spermidine, and putrecine) (Fig. 1). Prostate cancer usually shows an increased concentration of $\mathrm{Ch}$ and reduction of $\mathrm{Cit}$ and polyamines. Several studies have shown the benefit of adding MRSI to MRI in the evaluation of prostate cancer [2-13]. Studies have shown the ability of MRSI to improve the cancer detection rate in patients with high PSA [2]; moreover, MRSI has shown itself promising in assessment of cancer aggressiveness $[12,13]$. The accuracy of MRSI is generally accepted but it is important to avoid magnetic field distortions that may influence the MR spectrum. Moreover, MRSI requires a long acquisition time and more expertise; MRSI does not directly depict the peri-prostatic area and is often affected by artefacts.

Dynamic contrast enhanced MRI (DCE-MRI) has been developed for the assessment of perfusion parameters allowing to differentiate cancer from normal tissue [19, 23-29] (Fig. 2). The advantages of this technique include the direct or indirect depiction of tumour vascularity; however, because of overlap of enhancement pattern with benign conditions such as prostatitis in the peripheral zone and benign prostate hyperplasia nodules in the transition zone, DCE MRI is not considered as a dominant imaging sequence in prostate cancer detection. DCE-MRI is often applied as an adjunct to T2-MRI and Diffusion weighted imaging (DWI) findings in multiparametric MRI approach [14]. DWI assesses the restriction of diffusion and the reduction of apparent diffusion coefficient (ADC) values in cancerous tissue [30-33] (Fig. 3). Despite significant differences in the mean ADC values between cancerous and normal tissues, individual variability may decrease

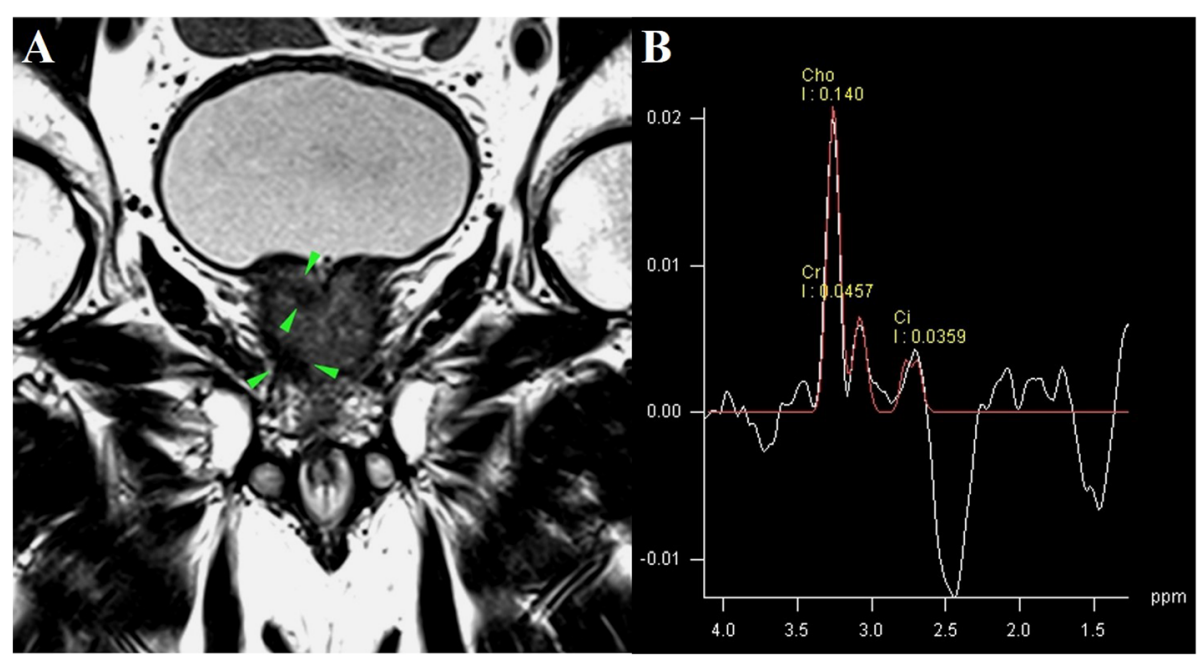

Fig. $1 \mathrm{MRSI}$ (a) in prostate cancer with correspondent metabolite spectrum (b) 


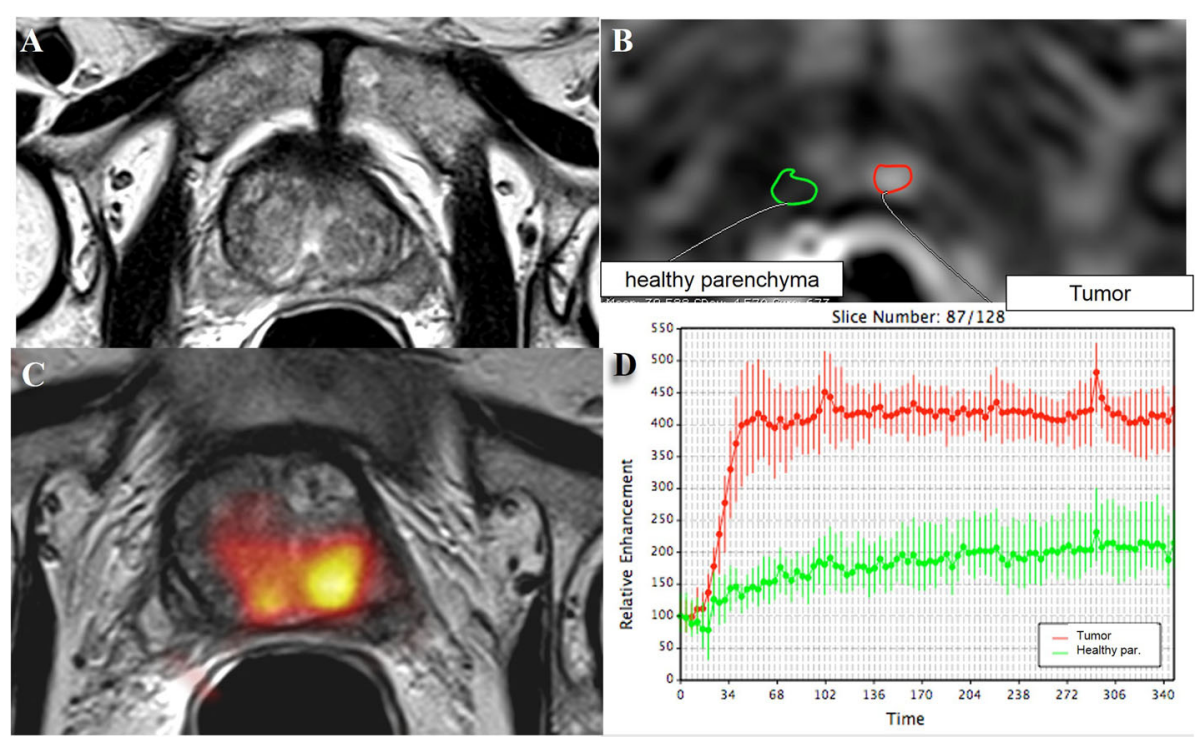

Fig. 2 DCE-MRI (a, b, c) with time intensity curve (d) for tumor area and healthy parenchyma area

ADC diagnostic accuracy for prostate cancer detection and localization [30-41].

Early promising data suggest that multimodal, also referred to as multiparametric MRI, combining several MRI modalities such as morphologic T2-MRI sequences and DCE-MRI or DWI and/or MRSI (functional MRI modalities), may be of additional value for the localization of prostate cancer and guidance of biopsy $[12,13,41-61]$. The combined use of T2-MRI and functional MRI modalities (DCE-MRI, DWI and/or MRSI) has been shown to improve cancer localization $[53,54]$ and cancer volume measurement [47] in the peripheral zone. Petrillo et al. [12] demonstrated that a combined score of morphological T2-MRI, DWI and MRSI had: (i) the highest sensitivity $(0.84)$ and negative predictive value (0.93) in prostate cancer detection; (ii) a significant correlation with Gleason score; and (iii) a statistically different median value between significant and not significant Gleason score.

A comprehensive evaluation in which both morphological and functional MRI modalities (DCE-MRI, DWI, MRSI) are used with an understanding of their particular advantages and disadvantages could be of help. In this manuscript, the authors will provide a systematic review of literature contributes about the role and the potentiality of T2-MRI, DCE-MRI, DWI, MRSI and their

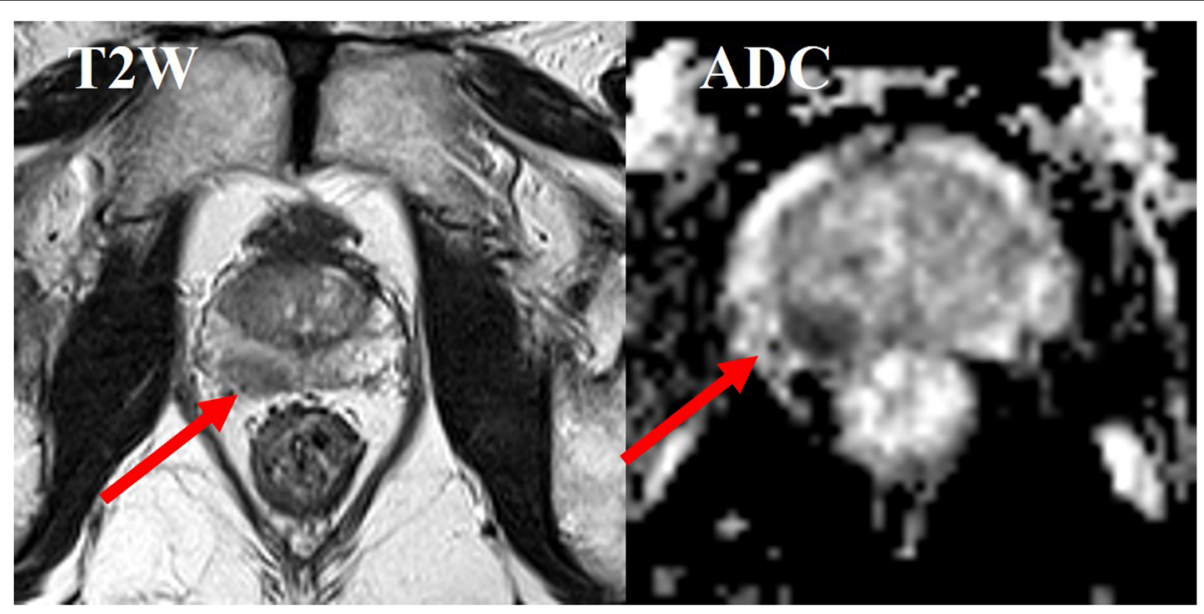

Fig. 3 T2-MRI with apparent diffusion coefficient map of DWI 
combinations in a multiparametric approach for prostate cancer detection.

\section{Methods}

The review is the result of autonomous studies without protocol and registration number.

\section{Search Criterion}

Several electronic databases were searched: PubMed (US National Library of Medicine, http://www.ncbi.nlm.nih.gov/pubmed), Scopus (Elsevier, http://www.scopus.com/), Web of Science (Thomson Reuters, http://apps.webofknowledge.com/) and Google Scholar (https://scholar.google.it/). The following search criteria have been used: "prostate cancer" AND "T2-weighted magnetic resonance imaging", "prostate cancer" AND "conventional magnetic resonance imaging", "prostate cancer" AND "dynamic contrast enhanced magnetic resonance imaging", "prostate cancer" AND "diffusion weighted magnetic resonance imaging"; "prostate cancer" AND "magnetic resonance spectroscopy imaging", "prostate cancer" AND "multimodal imaging", "prostate cancer" AND "multi-parametric imaging", "prostate cancer". The search covered the years from 2000 through 2016. Moreover, the reference lists of the found papers were analysed for papers not indexed in the electronic databases.

All titles and abstracts were analysed by two independent reviewers and exclusively the studies reporting MRI, DCE-MRI, DWI, MRSI and/or their combinations results in the prostate cancer detection and localization have been included.

If not otherwise stated, all the studies reviewed herein fulfill the following criteria: 1) English language; 2) thorough clinical characterization of the patients with prostate cancer studied by means MRI, DCE-MRI, DWI, MRSI and/or their combination and exclusion of studies using other diagnostic techniques; 2) articles, reviews and studies that did not present data about specificity, sensitivity, positive and negative predictive value of tests treated were excluded; 3 ) reviews, general overview articles and congress abstracts were excluded. There was no a minimum number of patients as an inclusion criteria due to the small number of studies for each imaging modality. Information extracted from each study included title, authors, year of publication, sample size, diagnostic modality, true and false positives number, true and false negatives number.

In this review, multimodal or multi-parametric MRI was considered as the combination of two diagnostic modalities. The combinations of two test can means: only one of the tests has to be positive for the result of the combination to be considered positive (indicated with "OR"), or all tests in the combination have to be positive before the result for the combination is considered positive (indicated with "AND").

\section{Data Analysis}

Review Manager (version 5.2) was used to perform data analysis for systematic review.

True and false positives number, true and false negatives number for each paper were collected and used to obtain the forest plots reporting the sensitivity, specificity values and relative $95 \%$ confidence intervals (CIs). Receiver operating characteristic (ROC) curves were also performed.

We assessed the risk of bias and the applicability at study level using the validated Quality Assessment of Diagnostic Accuracy Studies (QUADAS-2) scoring system. Four domains are scored: (1) patient selection; (2) index test, which describes the test being studied and how it was conducted and interpreted; (3) reference standard; and (4) flow and timing, which describe the flow of patient inclusion and exclusion and the interval between the index test and the reference standard. The quality assessment was performed by two independent reviewers. Any disagreements were resolved by discussion with a third reviewer.

\section{Results}

By using the search terms described earlier, we identified 425 studies from 2000 through 2016. 172 studies used other diagnostic techniques than MRI, DCE-MRI, DWI, MRSI and multimodal / multi-parametric imaging as a combination of two or more MRI modalities, 98 have different topic; 122 did not have sufficient data (did not report sensitivity and specificity). 33 studies remained for inclusion in our systematic review (Fig. 4).

Table 1 shows studies and participants number for each diagnostic modality. Table 2 reports studies characteristics. No study reporting the accuracy of MRSI combined with DWI was found.

22 studies [12, 17, 41, 44, 45, 52, 61-76] involving 2294 patients reported the diagnostic accuracy of T2MRI. 8 studies [17, 43, 52, 65, 68, 75-77] involving 1445 patients reported the diagnostic accuracy of DCE-MRI. 10 studies [12, 43-45, 61, 64, 66, 70, 73, 77] involving 618 patients reported the diagnostic accuracy of MRSI. 5 studies [52, 53, 65, 67, 68] involving 313 patients reported the diagnostic accuracy of T2-MRI combined to DCE-MRI. 5 studies [76, 78-81] involving 2121 patients reported the diagnostic accuracy of T2-MRI combined to DWI and DCE-MRI. 9 studies [44, 45, 61, 64, 66, 67, $70,73,82]$ involving 407 patients reported the diagnostic accuracy of T2-MRI combined to MRSI. 4 studies [2, 43, $75,77]$ involving 394 patients reported the diagnostic accuracy of MRSI combined to DCE-MRI. Only 2 studies (Petrillo et al. [12] and Haider et al. [41]) reported the 


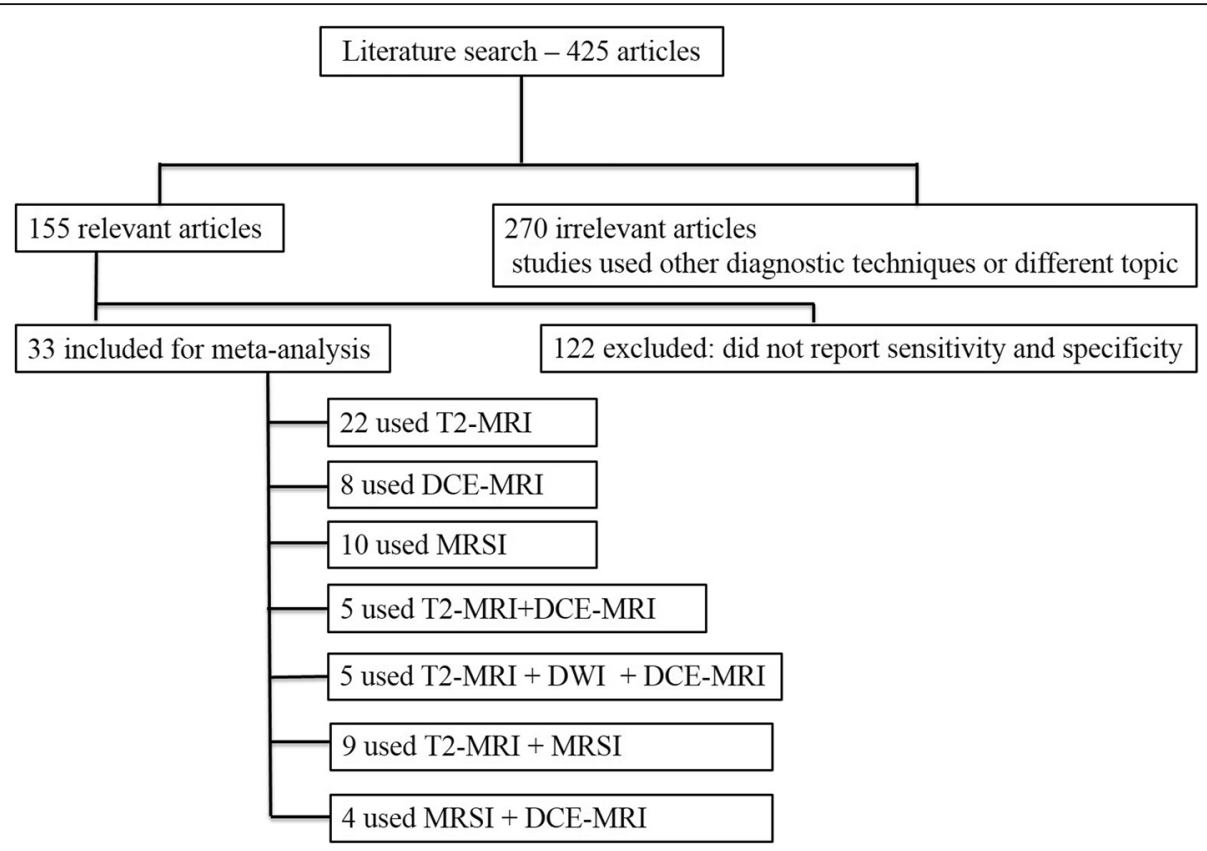

Fig. 4 Included and excluded studies in systematic review

diagnostic accuracy of T2-MRI combined with DWI with some discrepancies in the results: sensitivity of $64 \%$ and $81 \%$, specificity of $46 \%$ and $84 \%$, positive predictive value of $21 \%$ and $88 \%$ and negative predictive value of $89 \%$ and $83 \%$, respectively. One study [76] reporting the findings of DW-MRI alone was found (sensitivity and specificity of $87 \%$ and $92 \%$, respectively).

Figure 5 reports the values of TP (True Positive), FP (False Positive), FN (False Negative), TN (True Negative), sensitivity and specificity estimates and their confidence intervals (95\%) for each study; moreover, the figure reports in the name of the study whether the modalities combination is considered as "OR" or "AND". Figure 6 shows ROC for each diagnostic modality and their combinations. For the T2-MRI, we had a sensitivity of $75 \%$ and specificity of $60 \%$; for the DCE-MRI, the sensitivity was $80 \%$ and the specificity was $72 \%$; for the MRSI, the sensitivity was $89 \%$ and specificity was $69 \%$; for the combination T2-MRI

Table 1 Number of studies and participants for each diagnostic modality

\begin{tabular}{lll}
\hline Diagnostic modality & Studies & Participants \\
\hline T2-MRI & 22 & 2294 \\
MRSI & 10 & 618 \\
DCE-MRI & 8 & 1445 \\
T2-MRI combined with MRSI & 12 & 407 \\
T2-MRI combined with DCE-MRI & 5 & 313 \\
T2-MRI combined with DWI and DCE - MRI & 5 & 2121 \\
MRSI combined with DCE - MRI & 4 & 394 \\
\hline
\end{tabular}

and DCE-MRI, the sensitivity was $87 \%$ and specificity was 46\%; for the combination T2-MRI and MRSI, the sensitivity was $79 \%$ and specificity was $57 \%$; for the combination T2-MRI, DWI and DCE-MRI, the sensitivity was $81 \%$ and specificity was $84 \%$; and for the combination MRSI and DCE-MRI, the sensitivity was $83 \%$ and specificity was $83 \%$ (Table 3 ).

Overall, the quality was moderate (Fig. 7). In particular, the bias risk was unclear for some studies due to the lack of reporting on patient enrolment, on blinding to the index test during evaluation of the reference test. In the patient selection sphere, few studies had a high risk of bias because of inappropriate exclusion criteria. For the index test domain, high risk of bias was associated at the studies that did not provide a cut-off level and /or the readers were not blinded to the reference test. For the reference test domain, high risk of bias was associated at the studies where the reference standard was interpreted without blinding to the index test. No studies were excluded from the analysis based on the quality assessment.

Figure 8 shows Forest plot and Fig. 9 shows ROC curves for the use of ERC for 3467 patients versus the use of PAC for 3882 patients in the MRI acquisition using 1.5T scanner. For MRI studies that utilized ERC we obtained a pooled sensitivity, specificity, positive, negative predictive and accuracy value of $81 \%, 66 \%, 60 \%$ and $86 \%$ and $71 \%$, respectively. For MRI studies that utilized PAC we obtained a pooled sensitivity, specificity, positive, negative predictive value and accuracy of $78 \%, 64 \%, 61 \%$ and $82 \%$ and $68 \%$, respectively. The use of ERC did not increase 
Table 2 Studies characteristics. All studies used as a reference standard histopathological assessment of biopsied tissue obtained by TRUS

\begin{tabular}{|c|c|c|c|c|}
\hline Authors & Modality & N. Patients & ERC versus PAC & MR Scanner TESLA Intensity \\
\hline Amsellem-Ouazana et al. 2005 & T2, MRSI, T2 or MRSI & 42 & ERC & $1.5 \mathrm{~T}$ \\
\hline Babaian et al. 2000 & $\mathrm{~T} 2$ & 38 & PAC & $1.5 \mathrm{~T}$ \\
\hline Beyersdorff et al. 2002 & $\mathrm{~T} 2$ & 38 & ERC & $1.5 \mathrm{~T}$ \\
\hline Bhatia et al. 2007 & MRSI, T2 and MRSI & 21 & ERC & $1.5 \mathrm{~T}$ \\
\hline Bloch et al. 2007 & T2, DCE, T2 and DCE & 32 & ERC & $1.5 \mathrm{~T}$ \\
\hline Bloch et al. 2012 & T2 and DCE & 108 & ERC & $3 \mathrm{~T}$ \\
\hline Cheikh et al. 2009 & $\mathrm{~T} 2, \mathrm{DCE}, \mathrm{T} 2$ or DCE & 93 & PAC & $1.5 \mathrm{~T}$ \\
\hline Cirillo et al. 2008 & T2, MRSI, T2 or MRSI & 54 & ERC & $1.5 \mathrm{~T}$ \\
\hline Destefanis et al. 2009 & T2 or MRSI & 26 & ERC & $1.5 \mathrm{~T}$ \\
\hline Franiel et al 2011 & $\mathrm{~T} 2, \mathrm{~T} 2$ or MRSI, T2 or DCE & 54 & ERC & $1.5 \mathrm{~T}$ \\
\hline Haider 2007 & $\mathrm{~T} 2, \mathrm{~T} 2$ and $\mathrm{DCE}$ & 392 & ERC & $1.5 \mathrm{~T}$ \\
\hline Iwazawa et al. 2011 & T2 or DWI or DCE & 1424 & PAC & $1.5 \mathrm{~T}$ \\
\hline Kim et al. 2005 & T2, DCE & 954 & PAC & $1.5 \mathrm{~T}$ \\
\hline Kitajima et al. 2010 & T2 or DWI or DCE & 424 & PAC & $3 \mathrm{~T}$ \\
\hline Lattouf et al. 2007 & $\mathrm{~T} 2, \mathrm{DCE}, \mathrm{T} 2$ or DCE & 26 & ERC & $1.5 / 3 \mathrm{~T}$ \\
\hline Panebianco et al. 2010 & DCE, MRSI, MRSI and DCE & 150 & ERC & $1.5 \mathrm{~T}$ \\
\hline Perrotti et al. 2002 & $\mathrm{~T} 2$ & 74 & ERC & $1.5 / 3 \mathrm{~T}$ \\
\hline Prando et al. 2005 & T2, MRSI, T2 and MRSI & 42 & ERC & $1.5 \mathrm{~T}$ \\
\hline Sciarra et al. 2010 & DCE, MRSI, MRSI and DCE & 90 & ERC & $1.5 \mathrm{~T}$ \\
\hline Tamada et al. 2011 & T2, DCE, T2 or DWI or DCE & 50 & PAC & $1.5 \mathrm{~T}$ \\
\hline Tanimoto et al. 2007 & T2 or DWI or DCE & 83 & PAC & $1.5 \mathrm{~T}$ \\
\hline Testa et al. 2010 & T2, MRSI, T2 and MRSI, T2 or MRSI & 54 & ERC & $1.5 \mathrm{~T}$ \\
\hline Vilanova et al. 2011 & T2 or DWI or DCE & 140 & ERC & $1.5 \mathrm{~T}$ \\
\hline Wetter et al. 2005 & $\mathrm{~T} 2, \mathrm{MRSI}, \mathrm{T} 2$ and MRSI, T2 or MRSI & 6 & ERC & $1.5 \mathrm{~T}$ \\
\hline Yao et al. 2009 & $\mathrm{~T} 2$ & 41 & ERC & $3 T$ \\
\hline Younes et al. 2001 & $\mathrm{~T} 2$ & 27 & ERC & $1.5 \mathrm{~T}$ \\
\hline Yuen et al. 2004 & T2, MRSI, T2 and MRSI, T2 or MRSI & 24 & ERC & $1.5 \mathrm{~T}$ \\
\hline Petrillo et al. 2014 & T2, MRSI, T2 and MRSI & 136 & ERC & $1.5 \mathrm{~T}$ \\
\hline Petrillo et al. 2013 & MRSI and DCE & 106 & ERC & $1.5 \mathrm{~T}$ \\
\hline Heijmink et al. 2010 & $\mathrm{~T} 2$ & 46 & PAC & $3 T$ \\
\hline Sciarra et al. 2007 & T2, DCE, MRSI and DCE & 50 & ERC & $1.5 \mathrm{~T}$ \\
\hline
\end{tabular}

ERC endorectal coil, $P A C$ phase array coil

significantly the diagnostic accuracy in prostate cancer detection $(p>0.05$ at McNemar test).

\section{Discussions and Conclusions}

In this review, we collected the current evidence of the role of morphological T2-MRI and functional MRI modalities (DCE-MRI, DWI and MRSI) in the prostate cancer detection.

Among the 22 studies reporting the accuracy of T2MRI, 5 studies showed a sensitivity of $60 \%$ or lower. In addition, 4 studies reported specificity of $35 \%$ or lower for T2-MRI. Moreover, as reported by Roethke et al. [22] prostate cancer detection depends by tumour size: T2MRI cannot exclude prostate cancer with lesions smaller than $10 \mathrm{~mm}\left(0.4 \mathrm{~cm}^{3}\right)$, in this case, prostate cancer detection is lower than $13 \%$. Instead, the detection rate for lesions more than $20 \mathrm{~mm}\left(1.6 \mathrm{~cm}^{3}\right)$ was higher (45-89\%).

MRSI studies reported the $\mathrm{Cho}-\mathrm{Cr} / \mathrm{Ci}$ ratio used as the cut-off for a positive test result, which ranged from $>0.6$ to $>0.86$. All of the studies demonstrated a sensitivity of $\geq 83 \%$ apart from Petrillo et al. [12] and Yuen et al. [73] that reported a sensitivity of 76 and $71 \%$, respectively. Petrillo et al. [12] and Yuen et al. [73] suggested that influential factors to the low sensitivity reported might have been difficulties in ensuring the correspondence of TRUS biopsy spatial accuracies to suspicious areas on MRI. Moreover, the studies by Petrillo et al. [12], Prando et al. [44] and Testa et al. [45] reported low specificity 
T2w studies

\begin{tabular}{|c|c|c|c|c|c|c|}
\hline Study & TP & FP & $\mathrm{FN}$ & TN & Sensitivity $(95 \% \mathrm{Cl})$ & Specificity $(95 \% \mathrm{CI})$ \\
\hline Amsellem Ouazana st al. 2005 -T2w & 9 & 9 & 6 & 18 & $0.60[0.32,0.84]$ & $0.67[0.46,0.83]$ \\
\hline Babaian el al. $2000-T 2 W$ & 12 & 19 & 0 & 7 & $1.00[0.74,1.00]$ & $0.27[0.12,0.48]$ \\
\hline Beyersdortt ot al, 2002 - T2w & 12 & 19 & 0 & 7 & $1,00[0,74,1,00]$ & $0.27[0.12,0.48]$ \\
\hline Bhatia et sl. $2007-\mathrm{T} 2 \mathrm{w}$ & 2 & 4 & 0 & 15 & $1.00[0.16,1.00]$ & $0.79[0.54,0.94]$ \\
\hline Bloch of al. $2007-\mathrm{T} 2 \mathrm{w}$ & 7 & 3 & 4 & 18 & $0.64[0.31,0.89]$ & $0.86[0.64,0.97]$ \\
\hline Cheikh et al. $2009-\mathrm{T} 2 \mathrm{w}$ & 11 & 39 & 12 & 31 & $0.48[0.27,0.89]$ & $0.44[0.32,0.57]$ \\
\hline Cirilla of al, $2008-\mathrm{T} 2 \mathrm{w}$ & 17 & 13 & 0 & 24 & $1.00[0.80,1.00]$ & $0.65[0.47,0.80]$ \\
\hline Franiel at al $2011 . \mathrm{T} 2 \mathrm{w}$ & 18 & 22 & 3 & 11 & $0.86[0.84,0.97]$ & $0.33[0.18,0.52]$ \\
\hline Haider et al. $2007-\mathrm{T} 2 \mathrm{w}$ & 89 & 21 & 68 & 222 & $0.54[0.46,0.63]$ & $0.91[0.87,0.95]$ \\
\hline Heijmink st al. $2010 \cdot \mathrm{T} 2 \mathrm{w}$ & 1 & 0 & 14 & 31 & $0.07[0 . \infty 0,0.32]$ & $1.00[0.89,1.00]$ \\
\hline Kim et al. $2005-\mathrm{T} 2 \mathrm{~W}$ & 283 & 210 & 151 & 310 & $0.65[0.61,0.70]$ & $0.60[0.55,0.64]$ \\
\hline Lattouf ot al. $2007-T_{2} \mathrm{~N}$ & 13 & 10 & 1 & 2 & $0.93[0,66,1,00]$ & $0.17[0.02,0.48]$ \\
\hline Perrotti et s1. $2002-\mathrm{T} 2 \mathrm{w}$ & 16 & 17 & 1 & 40 & $0.94[0.71,1.00]$ & $0.70[0.57,0.82]$ \\
\hline Petrilo of al. $2014-\mathrm{T} 2 \mathrm{~N}$ & 19 & 63 & 6 & 48 & $0,76[0,55,0.91]$ & $0.43[0.34,0.53]$ \\
\hline Prando et al. $2005-\mathrm{T} 2 \mathrm{w}$ & 15 & 18 & 2 & 7 & $0.88[0.64,0.99]$ & $0.28[0.12,0.49]$ \\
\hline Sciars of al 2007 - T2W & 28 & 2 & 5 & 15 & $0.85[0.68,0.95]$ & $0.88[0.64,0.99]$ \\
\hline Tamada et al. 2011 - T2w & 21 & 2 & 14 & 13 & $0.60[0.42,0.76]$ & $0.87[0.60,0.98]$ \\
\hline Testa of $91.2010-T_{2} \mathrm{w}$ & 16 & 12 & 6 & 20 & $0.73[0.50,0.89]$ & $0.63[0.44,0.79]$ \\
\hline Wetter ef al. 2006 - T2W & 1 & 2 & 1 & 2 & $0.60[0.01,0.99]$ & $0.60[0.07,0.93]$ \\
\hline Yao et al. $2009-$ T2W & 14 & 10 & 1 & 16 & $0.23[0.68,1.00]$ & $0.62[0.41,0.80]$ \\
\hline Youres et al. $2001-\mathrm{T} 2 \mathrm{w}$ & 14 & 6 & 0 & 7 & $1.00[0,77,1.00]$ & $0.54[0.25,0.81]$ \\
\hline Yuen et sl. $2004-T 2 w$ & 4 & 4 & 3 & 13 & $0.57[0.18,0.90]$ & $0.76[0.50,0.93]$ \\
\hline
\end{tabular}

Yuen et al. 2004 - T2w

TP FP FN TN Sensitivity $195 \% \mathrm{Cl})$ Specificity $(95 \% \mathrm{CI})$ $\begin{array}{lllll}14 & 1 & 1 & 26\end{array}$ $\begin{array}{llll}2 & 5 & 0 & 14\end{array}$ $\begin{array}{llll}15 & 11 & 2 & 26\end{array}$ $\begin{array}{llll}53 & 7 & 11 & 79\end{array}$ $\begin{array}{llll}19 & 61 & 6 & 49\end{array}$ $\begin{array}{llll}17 & 14 & 0 & 11\end{array}$ $\begin{array}{llll}39 & 3 & 5 & 43\end{array}$ $\begin{array}{llll}20 & 18 & 2 & 14\end{array}$

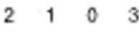
5829

\begin{tabular}{|c|c|c|}
\hline \multicolumn{2}{|c|}{$0.93[0,68,1.00]$} & $0.96[0.8$ \\
\hline \multicolumn{2}{|c|}{$1.00[0.16,1.00]$} & 0.74 \\
\hline \multicolumn{2}{|c|}{$0.88[0.64,0.99]$} & \\
\hline \multicolumn{2}{|c|}{$0.83[0.71,0.91]$} & \\
\hline \multicolumn{2}{|c|}{$0.76[0.55,0.91]$} & \\
\hline \multicolumn{2}{|c|}{$1.00[0.80,1.00]$} & \\
\hline \multicolumn{2}{|c|}{$0.89[0.75,0.96]$} & \\
\hline \multicolumn{2}{|c|}{$0.91[0.71,0.99]$} & \\
\hline \multirow{2}{*}{\multicolumn{2}{|c|}{$\begin{array}{l}1.00[0.16,1.00] \\
0.71[0.29,0.96]\end{array}$}} & 0 . \\
\hline & & \\
\hline \multicolumn{3}{|c|}{ ity (95\% cl) Specificity (95\% cr) } \\
\hline $59,1.00]$ & \multicolumn{2}{|c|}{$0.86[0.64,0.97]$} \\
\hline $.61,0.95 i$ & \multicolumn{2}{|c|}{$0.20[0.11,0.31]$} \\
\hline $93,0.97]$ & \multicolumn{2}{|c|}{$0.82[0.79,0.85]$} \\
\hline $.42,0.92]$ & \multicolumn{2}{|c|}{$0.33[0.10,0.65]$} \\
\hline $64,0.86]$ & \multicolumn{2}{|c|}{$0.90[0.81,0.95$} \\
\hline $51,0.84]$ & \multicolumn{2}{|c|}{$0.84[0.71,1.00]$} \\
\hline 65,0 & \multicolumn{2}{|c|}{$0.91[0.79 .0 .98]$} \\
\hline $7,0.88]$ & \multicolumn{2}{|c|}{$0.80[0.52,0.96]$} \\
\hline
\end{tabular}

TP FP FN TN Sensitivity (95\% Cl) Specificity (95\% Cl) $\begin{array}{llll}10 & 3 & 1 & 18\end{array}$ $\begin{array}{llll}19 & 56 & 4 & 14\end{array}$ $\begin{array}{llll}415 & 93 & 19 & 427\end{array}$ $\begin{array}{llll}10 & 8 & 4 & 4\end{array}$ $\begin{array}{llll}49 & 9 & 15 & 77\end{array}$ $\begin{array}{llll}23 & 1 & 10 & 16\end{array}$ $\begin{array}{llll}35 & 4 & 9 & 42\end{array}$ $\begin{array}{llll}26 & 3 & 9 & 12\end{array}$

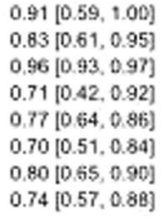

T2-MRI combined to DCE-MRI studies

Study

Bloxti ef al. 2007 - T2w and DCE Bloch of al. 2012 - T2w and DCE Cheikh ex al. 2009 - T2w or OCE Franiel ot al 2011 - T2W or DCE Lattouf et al. 2007 - T2w or DCE

TP FP FN TN Sensitivity (95\% Cl) Specificity $[95 \% \mathrm{CI})$ $\begin{array}{llll}10 & 1 & 20 & 0.91[0.59,1.00]\end{array}$ $\begin{array}{llllll}22 & \text { B } & 7 & 73 & 0.76 & {[0.56,0.90]}\end{array}$ $1959 \quad 4 \quad 11 \quad 0.83[0.61,0.95$ $\begin{array}{lllll}18 & 30 & 3 & 3 & 0.86[0.64,0.97]\end{array}$

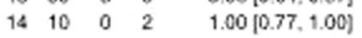

$0.85[0.76,1.00]$ $0.92[0.94,0.97]$ $0.16[0.08,0.26]$ $0.09[0.02,0.24]$ $0.17[0.02,0.48]$

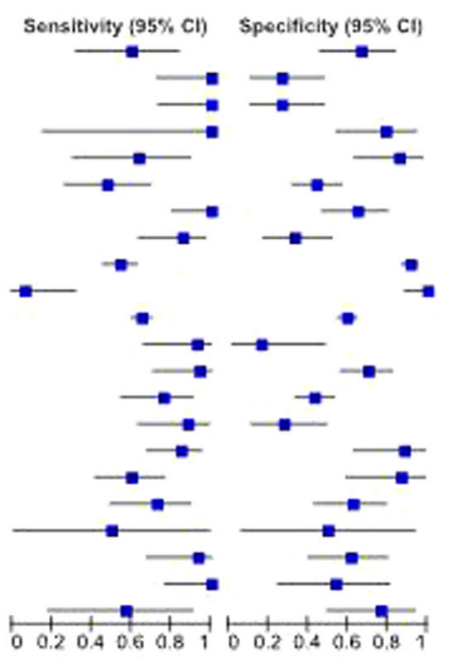

Sensitivity $(95 \% \mathrm{Cl}) \quad$ Specificity $(95 \% \mathrm{Cl}$

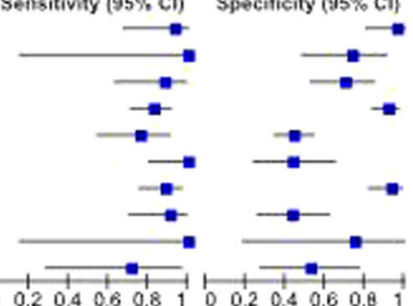

T2-MRI combined to DWI and DCE-MRI studies
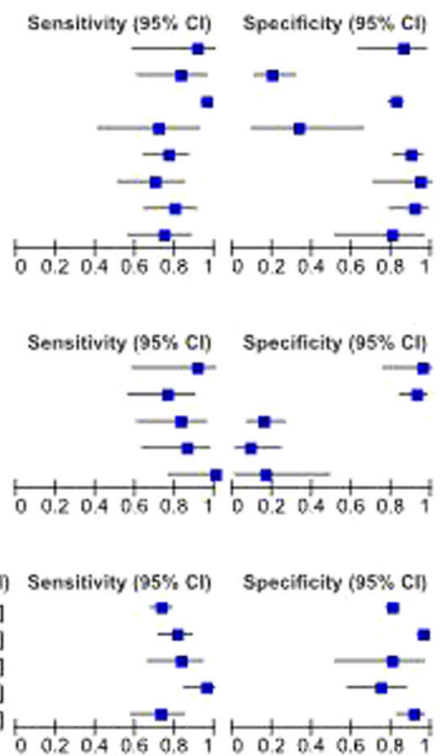

Study

Iwazeres es al. 2011 - T2W or OWI $\propto$ DCE Kitsima of al. 2010 - T2W or DWV or DCE Tamads ef al. 2011 - T2W of DWI of DCE Tanimos of al. 2CO7 - T2W or OWI or DCE Vilanova et al. 2011 - T2 $w$ or DW or DCE

\begin{tabular}{|c|c|c|c|c|c|c|}
\hline $\mathrm{T}$ & & FP & FN & TN & Sensitivity $(95 \% \mathrm{Cl})$ & ) Specificity $195 \%$ \\
\hline 23 & & 19 & 86 & 887 & $0.73[0.68,0.78]$ & $0.80[0.78,0.8$ \\
\hline & & 14 & 19 & 311 & $0.81[0.72,0.88]$ & $0.98[0,93,0.9$ \\
\hline & & 3 & 6 & 12 & $0.83[0.66,0.93]$ & $0.80[0.52,0.8$ \\
\hline & & 10 & 2 & 29 & $0.95[0.85,0.99]$ & $0.74[0,58,0.8$ \\
\hline & & 8 & 14 & 81 & $0.73[0.58,0.84]$ & $0.91[0.83,0.9$ \\
\hline TP & FP & $\mathrm{FN}$ & $T N$ & \multicolumn{2}{|c|}{ Sensitivity $\langle 25 \% \mathrm{Cl}\rangle=$} & Specificity $(95 \% \mathrm{cl})$ \\
\hline 62 & 8 & 4 & 75 & & $0.94[0.85,0.98]$ & \multirow{2}{*}{$\begin{array}{l}0.80[0.82,0.96] \\
0.49[0.39,0.60]\end{array}$} \\
\hline 11 & 48 & 4 & 45 & & $0.73[0.45,0.92]$ & \\
\hline 29 & 0 & 4 & 16 & & $0.88[0.72,0.97]$ & $1.00[0.79 .1 .00]$ \\
\hline 33 & 3 & 11 & 43 & & $0.75[0.60,0.87]$ & $0.93[0.82,0.99]$ \\
\hline
\end{tabular}

0.20 .4060 .8100 .20 .40 .60 .81

MRSI combined to DCE-MRI studies

Study

Panebianca en al. 2010 - MRSSI and DCE Perdona of al. 2013 - MRSI and DCE

Sciarra et al. 2007 - MRSI and DCE Sciarra ef al. 2010 - MRSI and DCE

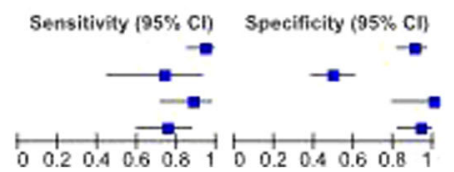

Fig. 5 Forest Plot including sensitivity, specificity estimates and their confidence intervals (95\%) for each MRI modality and their combinations in a multiparametric MRI approach 


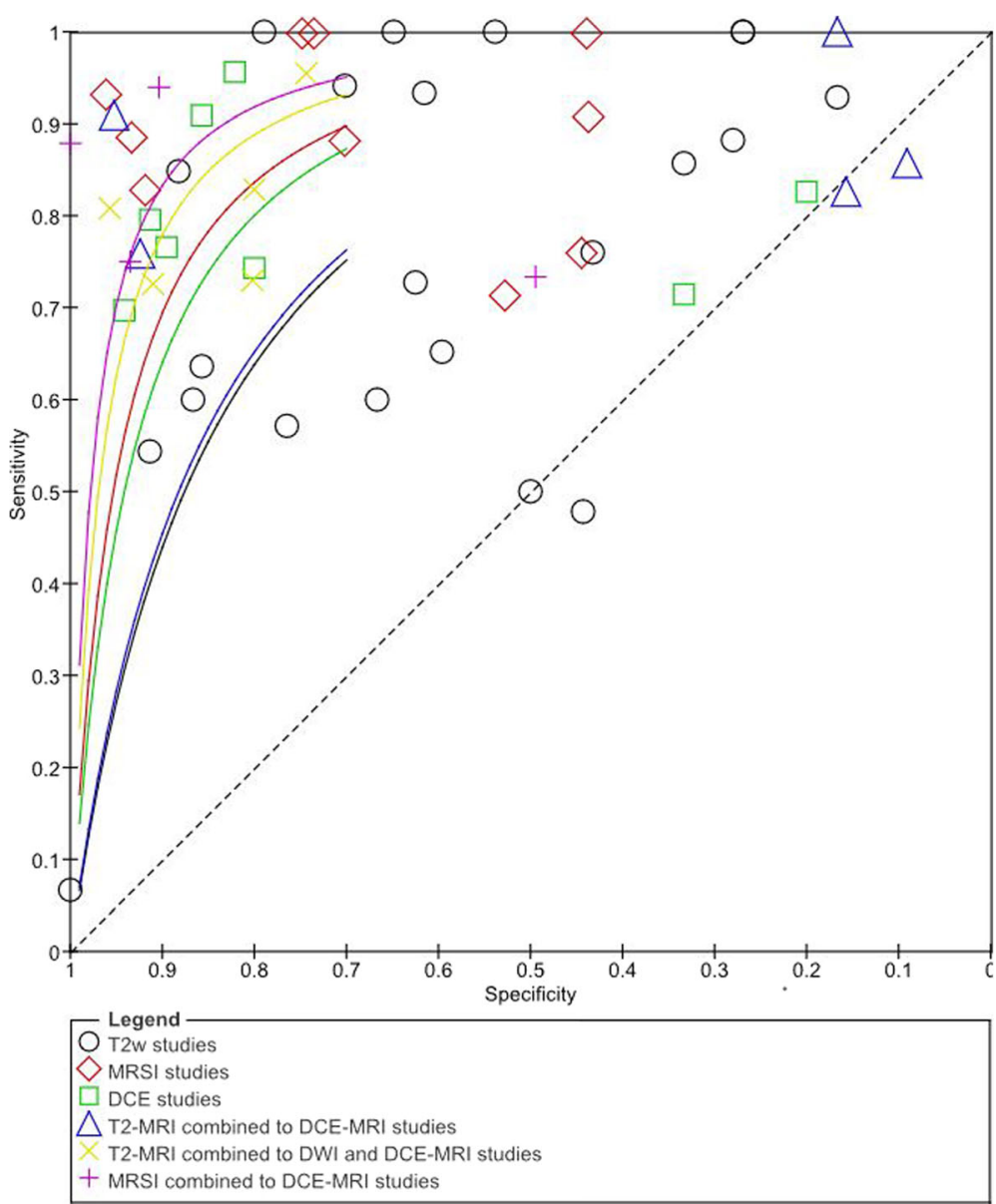

Fig. 6 Estimated Summary ROC curves and original data points for each MRI modality and their combinations in a multiparametric MRI approach

(44-46\%). Testa et al. [45] suggested that the low specificity in their study was probably determined by the lower $\mathrm{Cho}+\mathrm{Cr} / \mathrm{Ci}$ ratio used (actual value not reported) compared with cut-offs used by other studies.

Concerning to DCE-MRI, Engelbrecht et al. [28] reported the usefulness of relative peak enhancement and washout rate for prostate cancer detection and localization in the peripheral zone and gland central region (areas under the receiver operating characteristic curve were 0.93 and 0.82, respectively). Kim et al. [19] demonstrated, instead, that the wash-in rate was more accurate for the detection of prostate cancer in the peripheral zone (wash-in rate sensitivity and specificity of peripheral zone cancer detection were $96 \%$ and 97\%). However, they also observed significant overlap between the wash-in rate for cancer and normal tissue in the transitional zone. Moreover, some limitations of this modality were reported such as the inadequate depiction of

Table 3 Performance pooled analysis for MRI, DWI, DCE-MRI, PET/CT and multimodal imaging

\begin{tabular}{|c|c|c|c|c|c|}
\hline Performance Pooled Analysis & Sensitivity & Specificity & PPV & NPV & ACC \\
\hline T2-MRI & 75,12 & 59,82 & 55,38 & 81,51 & 65,21 \\
\hline DCE-MRI & 80,08 & 72,01 & 74,90 & 75,37 & 73,58 \\
\hline MRSI & 89,14 & 68,58 & 59,71 & 92,49 & 74,81 \\
\hline T2-MRI combined with DCE-MRI & 87,02 & 45,82 & 57,93 & 81,96 & 62,88 \\
\hline T2-MRI combined with MRSI & 78,76 & 57,13 & 52,64 & 84,46 & 63,39 \\
\hline T2-MRI combined with DWI and DCE - MRI & 80,92 & 84,25 & 78,03 & 86,18 & 84,53 \\
\hline MRSI combined with DCE - MRI & 82,54 & 83,32 & 74,88 & 86,60 & 80,26 \\
\hline
\end{tabular}




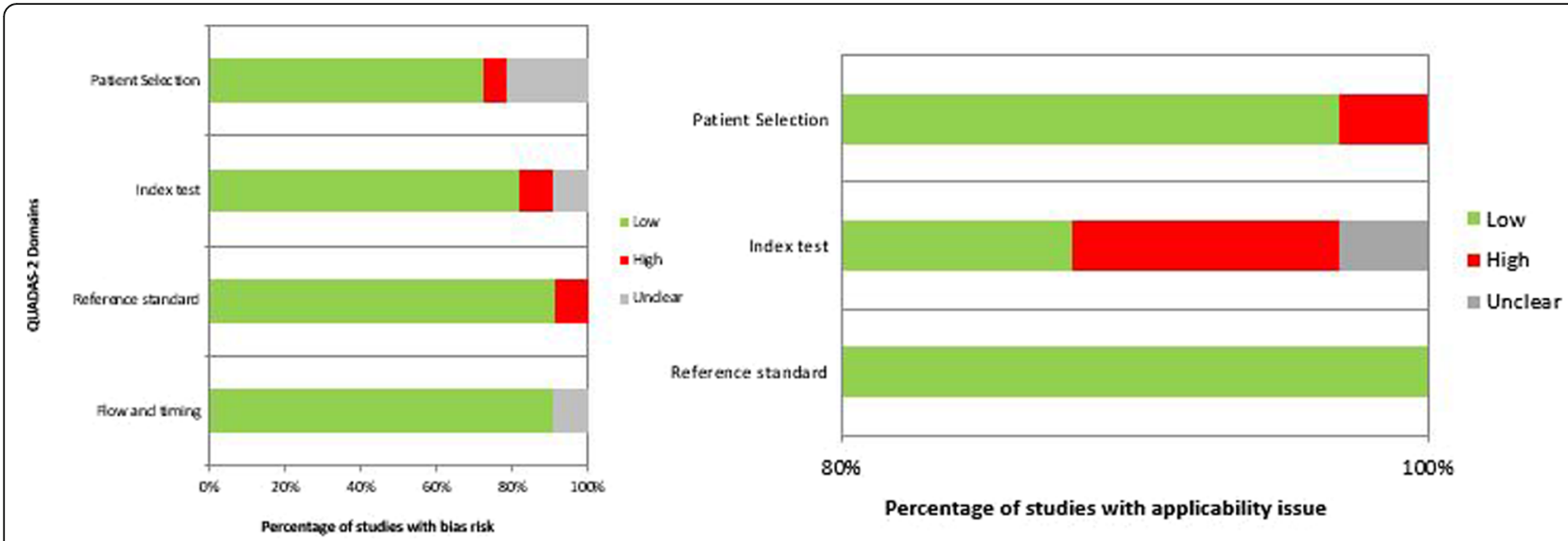

Fig. 7 Studies quality analysis by means QUADAS-2 domains

transitional zone cancer in patients with hypervascular benign prostatic hyperplasia. Hoeks et al. [20] reported that DCE-MRI did not show additional benefits compared to T2-MRI for detection of cancer in the transition zone. Instead, compared with the other DCE-MRI studies, the study by Sciarra et al. [75] reported high specificity (91\%).

In our analysis, the use of functional techniques in addition to T2-MRI appeared to have a large influence on sensitivity. In fact, ROC curves demonstrated that Multimodal Imaging combining MRSI and DCE-MRI or combining T2-MRI, DWI and DCE-MRI had the best accuracy in term of sensitivity and specificity (Fig. 7, Table 3). A multiparametric approach combining MRSI and DCE-MRI reached an increase of sensitivity of $8 \%$ and an increase of specificity of $23 \%$ while combining T2-MRI, DWI and DCE-MRI we obtained an increase in sensitivity and specificity of $6 \%$ and $24 \%$ respectively, compared to the morphological T2-MRI alone. Panebianco et al. [43] demonstrated that the combination of MRSI and DCE-MRI yielded $93.7 \%$ of sensitivity, $90.7 \%$ of specificity, $88.2 \%$ of positive predictive value, $95.1 \%$ of negative predictive value and $90.9 \%$ of accuracy in detecting prostate carcinoma. Similar results were provided by Petrillo et al., Perdonà et al. $[12,13]$ and Sciarra et al. [75].

Fusco et al. [83] in a recent study showed that combining morphological MRI, DWI, DCE-MRI and MRSI, an increase in sensitivity and specificity correlated to biopsy Gleason grade was obtained.

Our results are comparable with other review and meta-analysis [84-87]. Results of the Rooij et al. [87] meta-analysis suggested that T2-MRI with DWI and DCE-MRI is the best combination to provide better characterization of tumour in the prostate with a high overall sensitivity and specificity of $74 \%$ and $88 \%$, respectively, and negative predictive value ranging from
$65 \%$ to $94 \%$. In another study [88], multiparametric MRI showed good performance at detecting and ruling out clinically significant cancer, following at least one previous biopsy, with a negative predictive value of $95 \%$ using transperineal template systemic biopsy as the gold standard. The authors concluded that multiparametric MRI can therefore be used as a triage test following a negative biopsy and thereby identify patients who can avoid further biopsies.

Because prostate MRI interpretation can be subjective and inconsistent, suspicion scores for prostate cancer on MRI (Prostate Imaging and Reporting Archiving Data System [PI-RADS]) have been recently developed on a 1- to 5-point scale for improved standardization of MRI interpretation and reporting $[89,90]$ using a multiparametric approach with DCE-MRI, DWI and MRSI. A recent meta-analysis of 14 studies evaluating use of the PI-RADS scoring system for prostate cancer detection on multiparametric MRI showed good diagnostic accuracy [89]. These studies are not inserted in this systematic review because the PI-RADS scoring system is work in progress and PI-RADS version 2 has recently been published [90].

We also evaluated the differences in the diagnostic accuracy for prostate cancer detection between the use of ERC and PAC in MRI setting. Generally, use of a higher field strength (3.0T instead of $1.5 \mathrm{~T}$ ) or the use of endorectal coil improved the detection sensitivity for extracapsular extension (ECE) and seminal vesicle invasion (SVI) detection [91, 92]. ERC should be used for a field strength of $1.5 \mathrm{~T}$ in the absence of multiparametric MRI. ERC is useful for its capability to increase image resolution and to improve staging accuracy [91, 92]. Costa et al. [92] showed that the use of combined ERC and PAC for T2-MRI and DWI with 3T Magnetic Resonance scanner provides superior sensitivity for the detection of prostate cancer 
Study

Amsellem-Ouazana et al. 2005 - MRSI Amsellem-Ouazana et al. 2005- T2w or MRSI Amsellem-Ouazana et al. 2005-T2w Beyersdorff et al. 2002 - T2W

Bhatia et al. 2007 - MRSI

Bhatia et al. $2007-\mathrm{T} 2 \mathrm{~W}$

Bhatia et al. 2007- T2W and MRSI

Bloch et al. 2007 - DCE

Bloch et al. $2007-\mathrm{T} 2 \mathrm{~W}$

Bloch et al. 2007- T2W and DCE

Cirillo et al. 2008 - MRSI

Cirillo et al. 2008 - T2 or MRSI

Cirillo et al. 2008 - T2w

Destefanis et al. 2009 - T2w or MRSI

Franiel et al 2011 - T2w or DCE

Franiel et al 2011 - T2w or MRSI

Franiel et al $2011-\mathrm{T} 2 \mathrm{~W}$

Haider et al. $2007-\mathrm{T} 2 \mathrm{~W}$

Haider et al. $2007-\mathrm{T} 2 \mathrm{~W}$ and $\mathrm{DW}$

Panebianco et al. 2010 - DCE

Panebianco et al. 2010 - MRS

Panebianco et al. 2010 - MRSI and DCE

Perdona et al. 2013 - MRSI and DCE

Petrillo et a. 2014 - MRSI

Petrillo et al. 2014 - DWl

Petrillo et al. 2014 - T2W

Prando et al. 2005 - MRSI

Prando et al. 2005 - T2w

Prando et al. 2005 - T2W and MRSI

Sciarra et al. 2007 - DCE

Sciarra et al. 2007 - MRSI and DCE

Sciarra et al. $2007-\mathrm{T} 2 \mathrm{~W}$

Sciarra et al. 2010 - MRS|

Sciarra et al. 2010 - MRSI and DCE

Sciarra et al. 2010- DCE

Testa et al. 2010 - MRS।

Testa et al. $2010-$ T2 or MRSI

Testa et al. $2010-\mathrm{T} 2 \mathrm{~W}$

Testa et al. 2010- T2W and MRSI

Vilanova et al. $2011-\mathrm{T} 2 \mathrm{w}$ or DWl or DCE

Wetter et al. 2005 - MRSI

Wetter et al. 2005 - T2w

Wetter et al. 2005 - T2w and MRSI

Wetter et al. 2005 -T2w or MRSI

Younes et al. $2001-\mathrm{T} 2 \mathrm{~W}$

Yuen et al. 2004 - MRS

Yuen et al. $2004-\mathrm{T} 2 \mathrm{~W}$

Yuen et al. $2004-\mathrm{T} 2 \mathrm{~W}$ and MRSI

Yuen et al. $2004-T 2 w$ or MRS

\section{MRI with PAC 1.5T}

Study

Babaian et al. 2000 - T2W

Cheikh et al. 2009- DCE

Cheikh et al. $2009-\mathrm{T} 2 \mathrm{~W}$

Cheikh et al. $2009-\mathrm{T} 2 \mathrm{w}$ or DCE

Iwazawa et al. $2011-\mathrm{T} 2 \mathrm{w}$ or DW or DCE

Kim et al. 2005 - DCE

Kim et al. $2005-\mathrm{T} 2 \mathrm{w}$

Tamada et al. 2011 - DCE

Tamada et al. 2011 - T2w

Tamada et al. 2011 - T2w or DWI or DCE

Tanimoto et al. $2007-\mathrm{T} 2 \mathrm{~W}$ or DWI or DCE
TP FP FN TN Sensitivity $(95 \% \mathrm{Cl})$ Specificity $(\mathbf{9 5} \% \mathrm{Cl})$

$\begin{array}{lllll}14 & 1 & 1 & 26 & 0.93[0.68,1.00]\end{array}$

$\begin{array}{lllll}14 & 21 & 1 & 6 & 0.93[0.68,1.00]\end{array}$

$\begin{array}{llllll}9 & 9 & 6 & 18 & 0.60[0.32,0.84]\end{array}$

$\begin{array}{lllll}12 & 19 & 0 & 7 & 1.00[0.74,1.00]\end{array}$

$\begin{array}{lllll}2 & 5 & 0 & 14 & 1.00[0.16,1.00]\end{array}$

$\begin{array}{lllll}2 & 4 & 0 & 15 & 1.00[0.16,1.00]\end{array}$

$\begin{array}{lllll}2 & 3 & 0 & 16 & 1.00[0.16,1.00]\end{array}$

$\begin{array}{lllll}10 & 3 & 1 & 18 & 0.91[0.59,1.00]\end{array}$

$\begin{array}{lllll}7 & 3 & 4 & 18 & 0.64 \\ 10.31,0.89]\end{array}$

$\begin{array}{lllll}10 & 1 & 1 & 20 & 0.91[0.59,1.00]\end{array}$

$\begin{array}{lllll}15 & 11 & 2 & 26 & 0.88[0.64,0.99]\end{array}$

$\begin{array}{lllll}17 & 18 & 0 & 19 & 1.00[0.80,1.00]\end{array}$

$\begin{array}{lllll}17 & 13 & 0 & 24 & 1.00[0.80,1.00]\end{array}$

$\begin{array}{rrrrr}9 & 15 & 0 & 2 & 1.00[0.66,1.00]\end{array}$

$\begin{array}{lllll}20 & 25 & 1 & 8 & 0.95[0.76,1.00]\end{array}$

$\begin{array}{lllll}18 & 30 & 3 & 3 & 0.86[0.64,0.97]\end{array}$

$\begin{array}{lllll}18 & 22 & 3 & 11 & 0.86[0.64,0.97]\end{array}$

$\begin{array}{llllll}81 & 21 & 68 & 222 & 0.54 & {[0.46,0.63]}\end{array}$

$\begin{array}{llll}120 & 39 & 29 & 204\end{array}$

$\begin{array}{llll}49 & 9 & 15 & 77\end{array}$

$\begin{array}{llll}53 & 7 & 11 & 79\end{array}$

$\begin{array}{llll}62 & 8 & 4 & 75\end{array}$

$\begin{array}{llll}11 & 46 & 4 & 45\end{array}$

$\begin{array}{llll}19 & 63 & 6 & 48\end{array}$

$\begin{array}{llll}19 & 61 & 6 & 49\end{array}$

$\begin{array}{llll}15 & 46 & 8 & 67\end{array}$

$\begin{array}{llll}17 & 14 & 0 & 11\end{array}$

$\begin{array}{llll}15 & 18 & 2 & 7\end{array}$

$\begin{array}{llll}12 & 4 & 5 & 21\end{array}$

$\begin{array}{llll}23 & 1 & 10 & 16\end{array}$

$\begin{array}{llll}29 & 0 & 4 & 16\end{array}$

$\begin{array}{llll}28 & 2 & 5 & 15\end{array}$

$\begin{array}{llll}35 & 4 & 9 & 42\end{array}$

$\begin{array}{llll}39 & 3 & 5 & 43\end{array}$

$\begin{array}{llll}33 & 3 & 11 & 43\end{array}$

$\begin{array}{llll}20 & 18 & 2 & 14\end{array}$

$\begin{array}{llll}20 & 21 & 2 & 11\end{array}$

$\begin{array}{llll}16 & 12 & 6 & 20\end{array}$

$\begin{array}{llll}16 & 9 & 6 & 23\end{array}$

$\begin{array}{llll}37 & 8 & 14 & 81\end{array}$

$\begin{array}{llll}2 & 1 & 0 & 3\end{array}$

$\begin{array}{llll}1 & 2 & 1 & 2\end{array}$

$\begin{array}{llll}2 & 2 & 0 & 2\end{array}$

$\begin{array}{llll}1 & 1 & 1 & 3\end{array}$

$\begin{array}{llll}14 & 6 & 0 & 7\end{array}$

$\begin{array}{llll}5 & 8 & 2 & 9\end{array}$

$\begin{array}{llll}4 & 4 & 3 & 13\end{array}$

$\begin{array}{lllr}7 & 0 & 9 & 8\end{array}$

$\begin{array}{llll}2 & 4 & 5 & 13\end{array}$

$0.81[0.73,0.87]$

$0.77[0.64,0.86]$

$0.83[0.71,0.91]$

$0.94[0.85,0.98]$

$0.73[0.45,0.92]$

$0.76[0.55,0.91]$

$0.76[0.55,0.91]$

$0.65[0.43,0.84]$

$1.00[0.80,1.00]$

$0.88[0.64,0.99]$

$0.71[0.44,0.90]$

$0.70[0.51,0.84]$

$0.88[0.72,0.97]$

$0.85[0.68,0.95]$

$0.80[0.65,0.90]$

$0.89[0.75,0.96]$

$0.75[0.60,0.87]$

$0.91[0.71,0.99]$

$0.91[0.71,0.99]$

$0.73[0.50,0.89]$

$0.73[0.50,0.89]$

$0.73[0.58,0.84]$

$1.00[0.16,1.00]$

$0.50[0.01,0.99]$

$1.00[0.16,1.00]$

$0.50[0.01,0.99]$

$1.00[0.77,1.00]$

$0.71[0.29,0.96]$

$0.57[0.18,0.90]$

$0.44[0.20,0.70]$

$0.29[0.04,0.71]$
$0.96[0.81,1.00]$

$0.22[0.09,0.42]$

$0.67[0.46,0.83]$

$0.27[0.12,0.48]$

$0.74[0.49,0.91]$

$0.79[0.54,0.94]$

$0.84[0.60,0.97]$

$0.86[0.64,0.97]$

$0.86[0.64,0.97]$

$0.95[0.76,1.00]$

$0.51[0.34,0.68]$

$0.65[0.47,0.80]$

$0.12[0.01,0.36]$

$0.24[0.11,0.42]$

$0.09[0.02,0.24]$

$0.33[0.18,0.52]$

$0.91[0.87,0.95]$

$0.84[0.79,0.88]$

$0.90[0.81,0.95]$

$0.92[0.84,0.97]$

$0.90[0.82,0.96]$

$0.49[0.39,0.60]$

$0.43[0.34,0.53]$

$0.45[0.35,0.54]$

$0.59[0.50,0.68]$

$0.44[0.24,0.65]$

$0.28[0.12,0.49]$

$0.84[0.64,0.95]$

$0.94[0.71,1.00]$

$1.00[0.79,1.00]$

$0.88[0.64,0.99]$

$0.91[0.79,0.98]$

$0.93[0.82,0.99]$

$0.93[0.82,0.99]$

$0.44[0.26,0.62]$

$0.34[0.19,0.53]$

$0.63[0.44,0.79]$

$0.72[0.53,0.86]$

$0.91[0.83,0.96]$

$0.75[0.19,0.99]$

$0.50[0.07,0.93]$

$0.50[0.07,0.93]$

$0.75[0.19,0.99]$

$0.54[0.25,0.81]$

$0.53[0.28,0.77]$

$0.76[0.50,0.93]$

$1.00[0.63,1.00]$

$0.76[0.50,0.93]$
$0.70[0.53,0.84]$
Sensitivity $(95 \% \mathrm{Cl}) \quad$ Specificity $(95 \% \mathrm{Cl})$
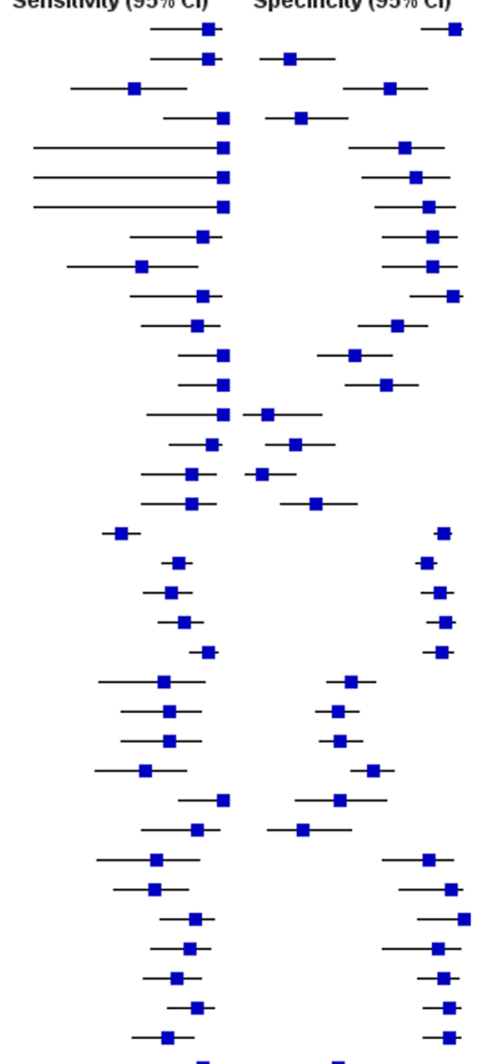

.
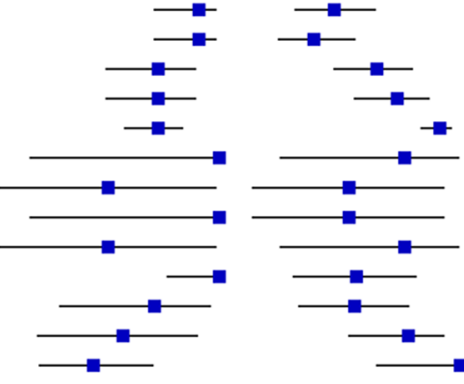

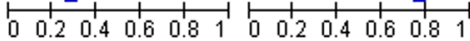

Fig. 8 Forest Plot including sensitivity, specificity estimates and their confidence intervals (95\%) for MRI acquired with ERC versus MRI acquired with PAC

TP FP FN TN Sensitivity $(95 \% \mathrm{Cl})$ Specificity $(95 \% \mathrm{Cl})$

$\begin{array}{lllllll}12 & 19 & 0 & 7 & 1.00[0.74,1.00] & 0.27[0.12,0.48]\end{array}$

$\begin{array}{lllllll}19 & 56 & 4 & 14 & 0.83[0.61,0.95] & 0.20[0.11,0.31]\end{array}$

$\begin{array}{lllllll}11 & 39 & 12 & 31 & 0.48[0.27,0.69] & 0.44[0.32,0.57]\end{array}$

$\begin{array}{lllllll}19 & 59 & 4 & 11 & 0.83[0.61,0.95] & 0.16[0.08,0.26]\end{array}$

$\begin{array}{llllll}232 & 219 & 86 & 887 & 0.73[0.68,0.78] & 0.80[0.78,0.83]\end{array}$

$\begin{array}{llllll}415 & 93 & 19 & 427 & 0.96[0.93,0.97] & 0.82[0.79,0.85]\end{array}$

$283 \quad 210151310-0.65[0.61,0.70]-0.60[0.55,0.64]$

$\begin{array}{llllll}21 & 2 & 14 & 13 & 0.60[0.42,0.76] & 0.87[0.60,0.98]\end{array}$

$\begin{array}{llll}26 & 3 & 9 & 12\end{array}$

$\begin{array}{llll}29 & 3 & 6 & 12\end{array}$

$\begin{array}{llll}42 & 10 & 2 & 29\end{array}$
$0.74[0.57,0.88]$

$0.83[0.66,0.93]$

$0.95[0.85,0.99]$
$0.80[0.52,0.96]$

$0.80[0.52,0.96]$
$0.74[0.58,0.87]$
Sensitivity $(95 \% \mathrm{Cl}) \quad$ Specificity $(95 \% \mathrm{Cl})$

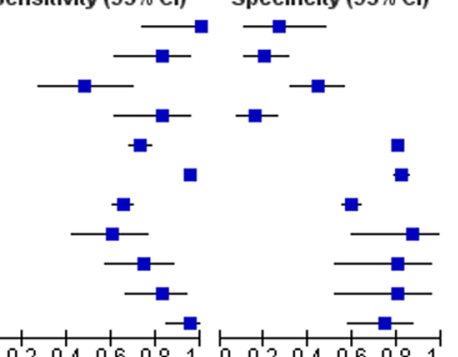




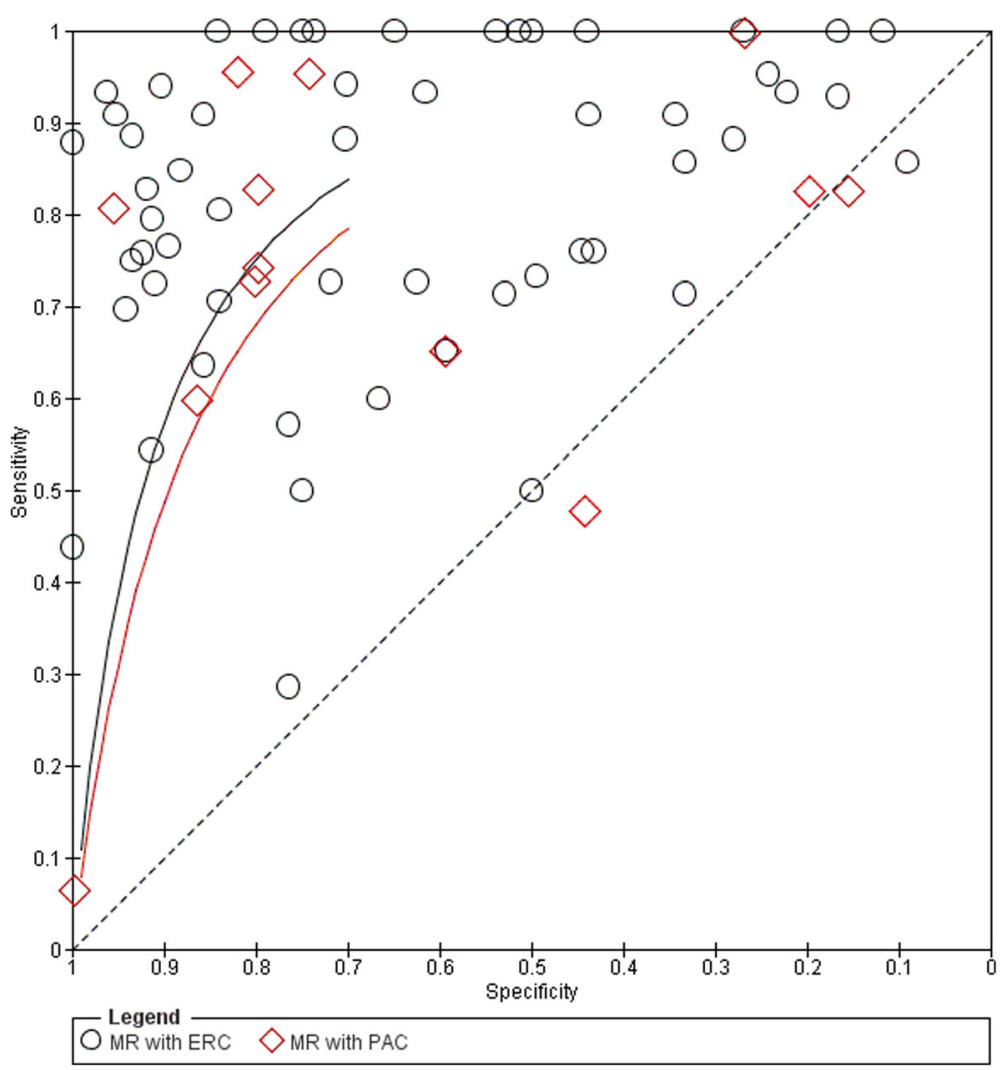

Fig. 9 Estimated summary ROC curves and original data points for MRI acquired with ERC versus MRI acquired with PAC

(78\%) compared to an examination performed without the ERC (43\%). Different results were reported from Baur et al. [93]: T2-MRI and DWI had a range of area under the curve with a PAC and with ERC-PAC of $0.95-0.99$ and 0.93-0.97, respectively. They concluded that T2-MRI and DWI performed at 3T for prostate cancer lesion identification and evaluation did not differ significantly with both coil setups and that patients preferred MRI without an ERC. Moreover, the ERC leads to deformity in the prostate contour, and the anatomical distortion resulting from it can potentially hinder the diagnosis and pathology correlation [94]. Another limitation is that patients with rectal stenosis or immediately after surgery or radiotherapy may not be good candidates for the use of the ERC during MRI examination. When higher field strengths or multichannel (8 channel or more) PAC and additional functional techniques were used, studies that used an ERC showed lower sensitivity and heterogeneous specificity than studies without an ERC [84]. Lee et al. [16] reported that the use of ERC in MRI acquisition did not significantly improve the staging of prostate cancer (AUC $=0.67$ versus 0.66 respectively with and without ERC) and presented several complications in $11.4 \%$ of patients.
Margolis et al. [95] reported that an ERC is not absolutely necessary and that the utility will depend on the performance of the scanner in question. Therefore, the use of multi-channel PAC during MRI acquisition could be an alternative considering comorbidity and could replace the use of an ERC. Also the European Society of Urogenital Radiology prostate MR guidelines reported in acquisition protocols minimum requirements that MRI can adequately be performed at $1.5 \mathrm{~T}$ using a good 8- to 16 channels PAC [96]. In our systematic review, we demonstrated that ERC yielded no additional benefit for the detection of prostate cancer: there was no statistically significant increase $(p>0.05$ at McNemar test) in sensitivity (81\% versus $78 \%$ ) and specificity (66\% versus $64 \%$ ). On the other side, the use of functional MRI in a multiparametric approach (MRSI and DCE-MRI or T2-MRI, DWI and DCE-MRI) improves the accuracy in prostate cancer detection allowing both the early cure and the guidance of biopsy. MRSI combined to DCE-MRI reached an increase of sensitivity of $8 \%$ and an increase of specificity of $23 \%$ while combining T2-MRI, DWI and DCE-MRI we obtained an increase in sensitivity and specificity of $6 \%$ and $24 \%$, respectively. 
About the limitations of this study: most papers reported on a limited number of patients. Because of the heterogeneity within the included studies with respect to patient selection, imaging protocols and analyses, this pooled analysis should be regarded as an indicator of the general performance of morphological T2-MRI and functional MRI in a multiparametric approach for prostate cancer detection and localization.

\section{Acknowledgements}

The authors are grateful to Alessandra Trocino, librarian at the National Cancer Institute of Naples, Italy. Moreover, for the collaboration, authors are grateful to Maria Bruno, Laura Galeani, Rita Guarino, Leandro Eto and Assunta Zazzaro.

\section{Funding}

Not applicable

\section{Availability of data and materials}

Data sharing not applicable to this article as no datasets were generated or analysed during the current study.

\section{Authors' contributions}

AP conceived of the study, and participated in its design, coordination and drafting of the manuscript. RF, MS participated in the studies collection and drafted the manuscript. RF, MS, VG, SS, AP participated in the studies collection. All authors read and approved the final manuscript.

\section{Ethics approval and consent to participate}

Not applicable

\section{Consent for publication}

Not applicable

\section{Competing interests}

The authors declare that they have no competing interests.

\section{Publisher's Note}

Springer Nature remains neutral with regard to jurisdictional claims in published maps and institutional affiliations.

\section{Author details \\ 'Radiology Unit, "Dipartimento di supporto ai percorsi oncologici Area Diagnostica, Istituto Nazionale Tumori - IRCCS - Fondazione G. Pascale", Via Mariano Semmola, Naples, Italy. ${ }^{2}$ Department of Electrical Engineering and Information Technologies, University "Federico II" of Naples, Via Claudio, Naples, Italy.}

Received: 23 March 2017 Accepted: 23 October 2017

Published online: 30 October 2017

\section{References}

1. Siegel RL, Miller KD, Jemal A. Cancer statistics, 2016. CA Cancer J Clin. 2016 Jan-Feb;66(1):7-30

2. Sfanos KS, De Marzo AM. Prostate cancer and inflammation: the evidence. Histopathology. 2012 Jan:60(1):199-215.

3. Whitaker NJ, Glenn WK, Sahrudin A, Orde MM, Delprado W, Lawson JS Human papillomavirus and Epstein Barr virus in prostate cancer: Koilocytes indicate potential oncogenic influences of human papillomavirus in prostate cancer. Prostate. 2013 Feb 15;73(3):236-41.

4. Zambrano A, Kalantari M, Simoneau A, Jensen UL, Villarreal LP. Detection of human polyomaviruses and papillomaviruses in prostatic tissue reveals the prostate as a habitat for multiple viral infections. Prostate. 2002 Dec 1;53(4):263-76

5. Kundu SD, Lee C, Billips BK, Habermacher GM, Zhang Q, Liu V, Wong LY, Klumpp DJ, Thumbikat $P$. The toll-like receptor pathway: a novel mechanism of infection-induced carcinogenesis of prostate epithelial cells. Prostate. 2008 Feb 1;68(2):223-9.
6. Sutcliffe S, Nevin RL, Pakpahan R, Elliott DJ, Cole SR, De Marzo AM, Gaydos CA, Isaacs WB, Nelson WG, Sokoll LJ, Zenilman JM, Cersovsky SB, Platz EA. Prostate involvement during sexually transmitted infections as measured by prostate-specific antigen concentration. Br J Cancer. 2011 Aug 23;105(5):602-5.

7. Singh N, Hussain S, Kakkar N, Singh SK, Sobti RC, Bharadwaj M. Implication of high risk human papillomavirus HR-HPV infection in prostate cancer in Indian population-a pioneering case-control analysis. Sci Rep. 2015 Jan 16;5:7822.

8. Bae JM. Human papillomavirus 16 infection as a potential risk factor for prostate cancer: an adaptive meta-analysis. Epidemiol Health. 2015 Feb 11;37:e2015005.

9. Brenes Bermúdez FJ, Alcántara Montero A. [Early detection or screening in the prevention of prostate cancer?]. Semergen. 2016 Mar 5. pii: S1138-3593(16)00046-0.

10. De Visschere PJL, Briganti A, Fütterer JJ, et al. Role of multiparametric magnetic resonance imaging in early detection of prostate cancer. Insights into Imaging. 2016;7(2):205-14

11. Javali TD, Dwivedi DK, Kumar R, Jagannathan NR, Thulkar S, Dinda AK. Magnetic resonance spectroscopy imaging-directed transrectal ultrasound biopsy increases prostate cancer detection in men with prostate-specific antigen between 4-10 ng/mL and normal digital rectal examination. Int J Urol. 2014 Mar;21(3):257-62.

12. Petrillo A, Fusco R, Setola SV, Ronza FM, Granata V, Petrillo M, et al. Multiparametric MRI for prostate cancer detection: performance in patients with prostate-specific antigen values between 2.5 and $10 \mathrm{ng} / \mathrm{mL}$. J Magn Reson Imaging. 2014 May;39(5):1206-12.

13. Perdonà S, Di Lorenzo G, Autorino R, Buonerba C, De Sio M, Setola SV, et al. Combined magnetic resonance spectroscopy and dynamic contrast-enhanced imaging for prostate cancer detection. Urol Oncol. 2013 Aug;31(6):761-5

14. Ghai S, Haider MA. Multiparametric-MRI in diagnosis of prostate cancer. Indian J Urology : IJU : J Urological Society of India. 2015;31(3):194-201.

15. Engelbrecht MR, Jager GJ, Laheij RJ, Verbeek AL, van Lier HJ, Barentsz JO. Local staging of prostate cancer using magnetic resonance imaging: a meta-analysis. Eur Radiol. 2002;12:2294-302.

16. Lee SH, Park KK, Choi KH, Lim BJ, Kim JH, Lee SW, et al. Is endorectal coil necessary for the staging of clinically localized prostate cancer? Comparison of non-endorectal versus endorectal MR imaging. World J Urol. 2010 Dec;28(6):667-72.

17. Kim BS, Kim T-H, Kwon TG, Yoo ES. Comparison of Pelvic Phased-Array versus Endorectal Coil Magnetic Resonance Imaging at 3 Tesla for Local Staging of Prostate Cancer. Yonsei Medical J. 2012;53(3):550-6.

18. Wang L, Mazaheri Y, Zhang J, Ishill NM, Kuroiwa K, Hricak H. Assessment of biologic aggressiveness of prostate cancer: correlation of MR signal intensity with Gleason grade after radical prostatectomy. Radiology. 2008 Jan:246(1):168-76.

19. Oto A, Yang C, Kayhan A, Tretiakova M, Antic T, Schmid-Tannwald C, Eggener S, Karczmar GS, Stadler WM. Diffusion-weighted and dynamic contrast-enhanced MRI of prostate cancer: correlation of quantitative MR parameters with Gleason score and tumor angiogenesis. AJR Am J Roentgenol. 2011 Dec;197(6):1382-90.

20. Hoeks CM, Hambrock T, Yakar D, Hulsbergen-van de Kaa CA, Feuth T, Witjes JA, et al. Transition zone prostate cancer: detection and localization with 3-T multiparametric MR imaging. Radiology. 2013 Jan;266(1):207-17.

21. Kim JK, Hong SS, Choi YJ, Park SH, Ahn H, Kim CS, et al. Wash-in rate on the basis of dynamic contrast-enhanced MRI: usefulness for prostate cancer detection and localization. J Magn Reson Imaging. 2005;22:639-46.

22. Roethke MC, Lichy MP, Jurgschat L, Hennenlotter J, Vogel U, Schilling D, et al. Tumor size dependent detection rate of endorectal MRI of prostate cancer-a histopathologic correlation with whole-mount sections in 70 patients with prostate cancer. Eur J Radiol. 2011 Aug;79(2):189-95.

23. Brawer MK, Deering RE, Brown M, Preston SD, Bigler SA. Predictors of pathologic stage in prostatic carcinoma: the role of neovascularity. Cancer. 1994;73:678-87

24. Buckley DL, Roberts C, Parker GJ, Logue JP, Hutchinson CE. Prostate cancer: evaluation of vascular characteristics with dynamic contrast enhanced T1-weighted MR imaging —initial experience. Radiology. 2004:233:709-15.

25. Bonekamp D, Jacobs MA, El-Khouli R, Stoianovici D, Macura KJ. Advancements in MR imaging of the prostate: from diagnosis to interventions Radiographics. Review. 2011 May-Jun;31(3):677-703. 
26. Turnbull LW, Buckley DL, Turnbull LS, Liney GP, Knowles AJ. Differentiation of prostatic carcinoma and benign prostatic hyperplasia: correlation between dynamic Gd-DTPA-enhanced MRI and histopathology. J Magn Reson Imaging. 1999;9:311-6.

27. Rouviere O, Raudrant A, Ecochard R. olin-Pangaud C, Pasquiou C, Bouvier R, et al. Characterization of time-enhancement curves of benign and malignant prostate tissue at dynamic MRI. Eur Radiol. 2003;13:931-42.

28. Engelbrecht MR, Huisman HJ, Laheij RJ, Jager GJ, van Leenders GJ, Hulsbergen-Van De Kaa CA, et al. Discrimination of prostate cancer from normal peripheral zone and central gland tissue by using dynamic contrast-enhanced MR imaging. Radiology. 2003;229:248-54.

29. Padhani AR, MacVicar AD, Gapinski CJ, Dearnaley DP, Parker GJ, Suckling J, et al. Effects of androgen deprivation on prostatic morphology and vascular permeability evaluated with MR imaging. Radiology. 2001;218:365-74.

30. Eis M, Els T, Hoehn-Berlage M, Hossmann KA. Quantitative diffusion MR imaging of cerebral tumor and edema. Acta Neurochir Suppl (Wien). 1994;60:344-6.

31. Eis $\mathrm{M}$, Els $\mathrm{T}$, Hoehn-Berlage M. High resolution quantitative relaxation and diffusion MRI of three different experimental tumors in rat. Magn Reson Med. 1995;34:835-44.

32. Sugahara T, Korogi Y, Kochi M, Ikushima I, Shigematu Y, Hirai T, et al. Usefulness of diffusion-weighted MRI with echo-planar technique in the evaluation of cellularity in gliomas. J Magn Reson Imaging. 1999;9:53-60.

33. Castillo M, Smith JK, Kwock L, Wilber K. Apparent diffusion coefficients in the evaluation of highgrade cerebral gliomas. AJNR Am J Neuroradiol. 2001;22:60-4.

34. Sato C, Naganawa S, Nakamura T, Kumada H, Miura S, Takizawa O, et al. Differentiation of non cancerous tissue and cancer lesions by apparent diffusion coefficient values in transition and peripheral zones of the prostate. J Magn Reson Imaging. 2005;21:258-62.

35. Hosseinzadeh K, Schwarz SD. Endorectal diffusion-weighted imaging in prostate cancer to differentiate malignant and benign peripheral zone tissue. J Magn Reson Imaging. 2004;20:654-61.

36. Chan I, Wells W 3rd, Mulkern RV, Mulkern RV, Haker S, Zhang J, et al. Detection of prostate cancer by integration of line-scan diffusion, T2-mapping and T2-weighted magnetic resonance imaging; a multichannel statistical classifier. Med Phys 2003;30:2390-2398.

37. Shimofusa R, Fujimoto H, Akamata H, Motoori K, Yamamoto S, Ueda T, et al. Diffusion-weighted imaging of prostate cancer. J Comput Assist Tomogr. 2005;29:149-53.

38. Tan $\mathrm{CH}$, Wei W, Johnson V, Kundra V, Diffusion-weighted MRI. in the detection of prostate cancer: meta-analysis. AJR Am J Roentgenol. 2012 Oct;199(4):822-9.

39. Emad-Eldina S, Halima M, Metwallya L, Mahmoud Abdel-Azizb R. Diffusionweighted MR imaging and ADC measurement in normal prostate, benign prostatic hyperplasia and prostate carcinoma. Egyptian J Radiology Nuclear Medicine Volume 45, Issue 2, June 2014, Pages 535-542.

40. Yağci AB, Ozari N, Aybek Z, Düzcan E. The value of diffusion-weighted MRI for prostate cancer detection and localization. Diagn Interv Radiol. 2011 Jun;17(2):130-4.

41. Haider MA, van der Kwast TH, Tanguay J, Evans AJ, Hashmi AT, Lockwood G, et al. Combined T2-weighted and diffusion-weighted MRI for localization of prostate cancer. AJR Am J Roentgenol. 2007 Aug;189(2):323-8.

42. Brown TR, Kincaid BM, Ugurbil KNMR. chemical shift imaging in three dimensions. Proc Natl Acad Sci U S A. 1982;79:3523-6.

43. Panebianco V, Sciarra A, Ciccariello M, Lisi D, Bernardo S, Cattarino S, et al. Role of magnetic resonance spectroscopic imaging (['H]MRSI) and dynamic contrast-enhanced MRI (DCE-MRI) in identifying prostate cancer foci in patients with negative biopsy and high levels of prostate-specific antigen (PSA). Radiol Med. 2010 Dec;115(8):1314-29.

44. Prando A, Kurhanewicz J, Borges AP. OliveiraEM Jr, Figueiredo E. Prostatic biopsy directed with endorectal MR spectroscopic imaging findings in patients with elevated prostate specific anti-gen levels and prior negative biopsy findings: early experience. Radiology. 2005;236:903-10.

45. Testa C, Schiavina R, Lodi R, Salizzoni E, Tonon C, D'Errico A, et al. Accuracy of MRI/MRSI-based transrectal ultrasound biopsy in peripheral and transition zones of the prostate gland in patients with prior negative biopsy. NMR Biomed. 2010;23:1017-26.

46. Zakian KL, Sircar K, Hricak H, Chen HN, Shukla-Dave A, Eberhardt S, et al. Correlation of proton MR spectroscopic imaging with Gleason score based on step-section pathologic analysis after radical prostatectomy. Radiology. 2005;234:804-14
47. Coakley FV, Kurhanewicz F, Lu Y, Jones KD, Swanson MG, Chang SD, et al. Prostate cancer tumor volume: measurement with endorectal MR and MR spectroscopic imaging. Radiology. 2002;223:91-7.

48. Stamey $T A$, McNeal JE, Freiha FS, Redwine E. Morphometric and clinical studies on 68 consecutive radical prostatectomies. J Urol. 1988;139:1235-41.

49. Giannarini $G$, Crestani A, Rossanese M, Ficarra V. Multiparametric Magnetic Resonance Imaging Targeted Biopsy for Early Detection of Prostate Cancer: All That Glitters Is Not Gold! Eur Urol. 2017 Jan 13. pii: S0302-2838(17)30017-9.

50. McNeal JE, Villers AA, Redwine EA, Freiha FS. S tamey TA. Capsular penetration in prostate cancer: significance for natural history and treatment. Am J Surg Pathol. 1990;14:240-7.

51. KK Y, Scheidler J, Hricak H, Vigneron DB, Zaloudek CJ, Males RG, et al. Prostate cancer: prediction of extracapsular extension with endorectal MR imaging and three-dimensional proton MR spectroscopic imaging. Radiology. 1999;213:481-8.

52. Bloch BN, Furman-Haran E, Helbich TH, Lenkinski RE, Degani H, Kratzik C, et al. Prostate cancer: accurate determination of extracapsular extension with high-spatial-resolution dynamic contrast-enhanced and T2-weighted MR imaging-initial results. Radiology. 2007;245:176-85.

53. Bloch BN, Genega EM, Costa DN, Pedrosa I, Smith MP, Kressel HY, et al. Prediction of prostate cancer extracapsular extension with high spatial resolution dynamic contrast-enhanced 3-T MRI. Eur Radiol. 2012;22:2201-10.

54. Wang L, Zhang J, Schwartz LH, Eisenberg H, Ishill NM, Moskowitz CS, et al. Incremental value of multiplanar cross-referencing for prostate cancer staging with endorectal MRI. AJR Am J Roentgenol. 2007;188:99-104.

55. Catalá V, Vilanova JC, Gaya JM, Algaba F, Martí T. Multiparametric magnetic resonance imaging and prostate cancer: what's new? Radiologia. 2017 Feb 21. pii: S0033-8338(17)30006-1.

56. Salerno J, Finelli A, Morash C, Morgan SC, Power N, Schieda N, Haider MA. Multiparametric magnetic resonance imaging for pre-treatment local staging of prostate cancer: A Cancer Care Ontario clinical practice guideline. Can Urol Assoc J. 2016 Sep-Oct; 10(9-10):E332-9.

57. De Visschere P, Lumen N, Ost P, Decaestecker K, Pattyn E, Villeirs G. Dynamic contrast-enhanced imaging has limited added value over T2weighted imaging and diffusion-weighted imaging when using PI-RADSv2 for diagnosis of clinically significant prostate cancer in patients with elevated PSA. Clin Radiol. 2017 Jan;72(1):23-32.

58. Thestrup KC, Logager V, Baslev I, Møller JM, Hansen RH, Thomsen HS. Biparametric versus multiparametric MRI in the diagnosis of prostate cancer. Acta Radiol Open. h Aug 17;5(8):2058460116663046.

59. Ueno Y, Tamada T, Bist V, Reinhold C, Miyake H, Tanaka U, Kitajima K, Sugimura K, Takahashi S. Multiparametric magnetic resonance imaging: Current role in prostate cancer management. Int J Urol. 2016 Jul;23(7):550-7.

60. Turkbey B, Brown AM, Sankineni S, Wood BJ, Pinto PA, Choyke PL. Multiparametric prostate magnetic resonance imaging in the evaluation of prostate cancer. CA Cancer J Clin. 2016 Jul;66(4):326-36. doi: 10.3322/caac.21333.

61. Amsellem-Ouazana D, Younes P, Conquy S, Peyromaure M, Flam T, Debre B, et al. Negative prostatic biopsies in patients with a high risk of prostate cancer. Is the combination of endorectal MRI and magnetic resonance spectroscopy imaging (MRSI) a useful tool? A preliminary study. Eur Urol. 2005;47:582-6.

62. Babaian RJ, Toi A, Kamoi K, Troncoso P, Sweet J, Evans R, et al. A comparative analysis of sextant and an extended 11-core multisite directed biopsy strategy. J Urol. 2000;163:152-7.

63. Beyersdorff D, Taupitz M, Winkelmann B, Fischer T, Lenk S, Loening SA, et al. Patients with a history of elevated prostate-specific antigen levels and negative transrectal US-guided quadrant or sextant biopsy results: value of MR imaging. Radiology. 2002;224:701-6.

64. Bhatia C, Phongkitkarun S, Booranapitaksonti D, Kochakarn W, Chaleumsanyakorn P. Diagnostic accuracy of MRI/MRSI for patients with persistently high PSA levels and negative TRUS-guided biopsy results. J Med Assoc Thai. 2007;90:1391-9.

65. Cheikh AB, Girouin N, Colombel M, Marechal JM, Gelet A, Bissery A, et al. Evaluation of T2-weighted and dynamic contrast-enhanced MRI in localizing prostate cancer before repeat biopsy. Eur Radiol. 2009;19:770-8. doi: 10.1007/s00330-008-1190-8

66. Cirillo S, Petracchini M, Della MP, Gallo T, Tartaglia V, Vestita E, et al. Value of endorectal MRI and MRS in patients with elevated prostate-specific antigen levels and previous negative biopsies to localize peripheral zone tumours. Clin Radiol. 2008;63:871-9.

67. Franiel T, Stephan C, Erbersdobler A, Dietz E, Maxeiner A, Hell N, et al. Areas suspicious for prostate cancer: MR-guided biopsy in patients with at least 
one transrectal US-guided biopsy with a negative finding - multiparametric MR imaging for detection and biopsy planning. Radiology. 2011;259:162-72.

68. Lattouf JB, Grubb RLIII, Lee SJ, Bjurlin MA, Albert P, Singh AK, et al. Magnetic resonance imagingdirected transrectal ultrasonography-guided biopsies in patients at risk of prostate cancer. BJU Int. 2007;99:1041-6.

69. Perrotti M, Ankem MK, Weiss RE, Epstein R, Decarvalho VS, Kattan M, et al. Endorectal MRI: adjunct to repeat biopsy in prostate cancer detection. The smart biopsy. J Urol. 2002;167:387.

70. Wetter A, Hubner F, Lehnert T, Fliessbach K, Vorbuchner M, Roell S, et al. Three-dimensional $1 \mathrm{H}$-magnetic resonance spectroscopy of the prostate in clinical practice: technique and results in patients with elevated prostate-specific antigen and negative or no previous prostate biopsies. Eur Radiol. 2005;15:645-52.

71. Yao DF, DeWolf WC, Sanda MG, Bloch BN, Genega EM, Berry AM, et al. Increased positive yield of clinically significant prostate cancer with MRI prompted biopsies. J Urol. 2009;181(Suppl. 1):782-3.

72. Younes P, Zerbib M, Saighi D, Conquy S, Thiounn N, Flam T, et al. Interest of endorectal MRI for patients with a high risk of prostate cancer but negative sextant biopsies. Eur Urol. 2001;39:148.

73. Yuen JS, Thng CH, Tan PH, Khin LW, Phee SJ, Xiao D, et al. Endorectal magnetic resonance imaging and spectroscopy for the detection of tumor foci in men with prior negative transrectal ultrasound prostate biopsy. J Urol. 2004;171:1482-6.

74. Heijmink SW, Fütterer JJ, Hambrock T, Takahashi S, Scheenen TW, Huisman $\mathrm{HJ}$, et al. Prostate cancer: body-array versus endorectal coil MR imaging at 3 T-comparison of image quality, localization, and staging performance. Radiology. 2007 Jul;244(1):184-95.

75. Sciarra A, Panebianco V, Salciccia S, Osimani M, Lisi D, Ciccariello M, et al. Role of dynamic contrast-enhanced magnetic resonance (MR) imaging and proton MR spectroscopic imaging in the detection of local recurrence after radical prostatectomy for prostate cancer. Eur Urol. 2008 Sep;54(3):589-600.

76. Tamada T, Sone T, Higashi H, Jo Y, Yamamoto A, Kanki A, et al. Prostate cancer detection in patients with total serum prostate-specific antigen levels of 4-10 $\mathrm{ng} / \mathrm{mL}$ : diagnostic efficacy of diffusion-weighted imaging, dynamic contrastenhanced MRI, and T2-weighted imaging. AJR. 2011;197:664-70.

77. Sciarra A, Panebianco V, Ciccariello M, Salciccia S, Cattarino S, Lisi D, et al. Value of magnetic resonance spectroscopy imaging and dynamic contrastenhanced imaging for detecting prostate cancer foci in men with prior negative biopsy. Clin Cancer Res. 2010;16:1875-83.

78. Iwazawa J, Mitani T, Sassa S, Ohue S. Prostate cancer detection with MRI: is dynamic contrast-enhanced imaging necessary in addition to diffusionweighted imaging? Diagn Interv Radiol. 2011;17:243-8.

79. Kitajima K, Kaji Y, Fukabori Y, Yoshida K, Suganuma N, Sugimura K. Prostate cancer detection with 3 T MRl: comparison of diffusion-weighted imaging and dynamic contrast-enhanced MRI in combination with T2-weighted imaging. J Magn Reson Imaging. 2010;31:625-31.

80. Tanimoto A, Nakashima J, Kohno H, Shinmoto H, Kuribayashi S. Prostate cancer screening: the clinical value of diffusion-weighted imaging and dynamic MR imaging in combination with T2-weighted imaging. J Magn Reson Imaging. 2007;25:146-52.

81. Vilanova JC, Barceló-Vidal C, Comet J, Boada M, Barceló J, Ferrer J, et al. Usefulness of prebiopsy multifunctional and morphologic MRI combined with free-to-total prostate-specific antigen ratio in the detection of prostate cancer. AJR Am J Roentgenol. 2011 Jun;196(6):W715-22.

82. Destefanis P, Bosio A, De Maria C, Bisconti A, Cugiani A, Negro CLA, et al. Targeted needle re-biopsy of the prostate after combination of endorectal MRI (ENDOMRI) and magnetic resonance spectroscopy (MRS) in patients with atypical small acinar proliferation (ASAP). Eur Urol Suppl. 2009;8:354

83. Fusco R, Sansone M, Petrillo M, Setola SV, Granata V, Botti G, et al. Multiparametric MRI for prostate cancer detection: Preliminary results on quantitative analysis of dynamic contrast enhanced imaging, diffusionweighted imaging and spectroscopy imaging. Magn Reson Imaging. 2016 Sep;34(7):839-45.

84. Loffroy R, Chevallier O, Moulin M, Favelier S, Genson PY, Pottecher P, et al. Current role of multiparametric magnetic resonance imaging for prostate cancer. Quant Imaging Med Surg. 2015 Oct;5(5):754-64.

85. Sankineni S, Osman M, Choyke PL. Functional MRI in Prostate Cancer Detection. Biomed Res Int. 2014;2014:590638.

86. Hegde JV, Mulkern RV, Panych LP, Fennessy FM, Fedorov A, Maier SE, et al. Multiparametric MRI of Prostate Cancer: An Update on State-of-the-Art
Techniques and Their Performance in Detecting and Localizing Prostate Cancer. J Magn Reson Imaging. 2013 May;37(5):1035-54.

87. de Rooij M, Hamoen EH, Witjes JA, Barentsz JO, Rovers MM. Accuracy of Magnetic Resonance Imaging for Local Staging of Prostate Cancer: A Diagnostic Meta-analysis. Eur Urol. 2016 Aug;70(2):233-45.

88. Abd-Alazeez M, Ahmed HU, Arya M, Charman SC, Anastasiadis E, Freeman A, et al. The accuracy of multiparametric MRI in men with negative biopsy and elevated PSA level-can it rule out clinically significant prostate cancer? Urol Oncol. 2014:32, 45:e17-22.

89. Hamoen EH, de Rooij M, Witjes JA, Barentsz JO, Rovers MM. Use of the prostate imaging reporting and data system (PI-RADS) for prostate cancer detection with multiparametric magnetic resonance imaging: A diagnostic meta-analysis. Eur Urol. 2015;67:1112-21.

90. American College of Radiology. MR Prostate Imaging Reporting and Data System version 2.0. [Accessed Jan 2015]. from http://www.acr.org/QualitySafety/Resources/PIRADS/

91. Chen H, Sutedjo J, Wang L, Yin X. Prostate Cancer Magnetic Resonance Spectroscopy Imaging at 1.5 and 3.0 T: A Meta-Analysis. Technol Cancer Res Treat. 2016 May 4.

92. Costa DN, Yuan Q, Xi Y, Rofsky NM, Lenkinski RE, Lotan Y, et al. Comparison of prostate cancer detection at 3-T MRI with and without an endorectal coil: A prospective, paired-patient study. Urol Oncol. 2016 Jun;34(6):255.e7-255.e13.

93. Baur AD, Daqqaq T, Wagner M, Maxeiner A, Huppertz A, Renz D, et al. T2- and diffusion-weighted magnetic resonance imaging at $3 T$ for the detection of prostate cancer with and without endorectal coil: An intraindividual comparison of image quality and diagnostic performance. Eur J Radiol. 2016 Jun;85(6):1075-84.

94. Shah ZK, Elias SN, Abaza R, Zynger DL, DeRenne LA, Knopp MV, et al. Performance comparison of 1.5-T endorectal coil MRI with 3.0-T nonendorectal coil MRI in patients with prostate cancer. Acad Radiol. 2015 Apr;22(4):467-74.

95. Margolis DJA, Multiparametric MRI. for Localized Prostate Cancer: Lesion Detection and Staging. BioMed Research Int. 2014;2014:684127.

96. Barentsz JO, Richenberg J, Clements R, Choyke P, Verma S, Villeirs G, Rouviere $\mathrm{O}$, Logager $\mathrm{V}$, Fütterer JJ. European Society of Urogenital Radiology. ESUR prostate MR guidelines 2012. Eur Radiol. 2012 Apr;22(4):746-57.

\section{Submit your next manuscript to BioMed Central and we will help you at every step:}

- We accept pre-submission inquiries

- Our selector tool helps you to find the most relevant journal

- We provide round the clock customer support

- Convenient online submission

- Thorough peer review

- Inclusion in PubMed and all major indexing services

- Maximum visibility for your research

Submit your manuscript at www.biomedcentral.com/submit
) Biomed Central 